UNITED STATES

DEPARTMENT OF THE INTERIOR

GEOLOGICAL SURVEY

345 Middlefield Road

Menlo Park, California 94025

\title{
NOTES ON A BROAD-BAND VARIANT OF THE NCER SEISMIC DATA MULTIPLEX SYSTEM FOR USE \\ WITH FIELD TAPE RECORDERS
}

by

Jerry P. Eaton

Open-file Report 76-87

1976

This report is preliminary and has

not been edited or reviewed for

conformity with Geological Survey

standards and nomenclature

Any use of trade names and trademarks in this publication is for descriptive purposes only and does not constitute endorsement by the U.S. Geological Survey. 
I. Introduction

II. Broad-band Multiplex System Design, Components, and Tests
a. Subcarrier frequencies and deviations
b. Test modulators
C. Discriminators
d. Modulator/discriminator compensation tests
e. Modulator/discriminator noise tests
f. Modulator/discriminator system response tests
g. Crosstalk tests

III. Broad-band System Recorded and Played Back on the Sony TC-126 Cassette Recorder
a. Sony TC-126 cassette recorder
b. Noise levels (dynamic range) of the broad-band system recorded and played back on the Sony
c. Crosstalk and system frequency response
d. Effectiveness of compensation
e. Channel usage, and elimination of channels

IV. Hybrid System Employing the P.I. 5100 5-Day Tape Recorder
a. P.I. 5100 tape recorder, test modulators, and playback system
b. Bias and modulation level tests
c. Hybrid system compensation test
d. FM channel output noise level versus output filter and cutoff frequency 
e. Noise tests of the hybrid system

f. Hybrid system frequency response

g. Crosstalk in the hybrid system

h. Compensation effectiveness in the hybrid system

i. Deletion of channels 


\section{Introduction}

Tests of the standard NCER multiplex system recorded and played back on both the Bell and Howell 3700B (about 0.1\% tape speed variation) and on the Sony TC-126 cassette recorder (about 1\% tape speed variation) showed that subtractive compensation employing a reference frequency multiplexed on the data track was remarkably effective in reducing tape-speed-variation-induced noise and, hence, in increasing the dynamic range of the record/playback system. ${ }^{1}$ Further tests suggested that the 0 to $30 \mathrm{hz}$ bandwidth of the standard system (8 data channels) might be increased substantially, at the "price" of reducing the number of data channels to 3 or 4 , without serious loss of dynamic range if subtractive compensation could be implemented effectively with the broaderband system. ${ }^{1}$

Two immediate applications of the broad-band system are apparent:

(1) use with the Sony $\mathrm{TC}-126$ cassette recorder in a broad-band refraction seismic system with maximum portability and low cost.

(2) Use with the Precision Instrument PI 5100 5-day tape recorder recording at 15/80 ips, with "record" center frequencies and deviations reduced by a factor of 5 , in a hybrid system with response to 20 or $30 \mathrm{hz}$, good dynamic range, and many (e.g. 14 to 21) data channels. This system would be played back at 15/16 ips and would require the broad-band (0 to 100 or $150 \mathrm{hz}$ ) discriminators to recover data frequencies of 0 to 20 or $30 \mathrm{hz}$.

The work described in these notes was undertaken to evaluate those two possible systems. It consisted of:

(1) setting up the appropriate test modulators,

1. Notes on some experiments on the applications of subtractive compensation to the USGS seismic magnetic tape recording and playback systems: USGS Open File Report, Aug 1975, J. P. Eaton. 
(2) modifying standard Develco discriminators to obtain the broad-band data discriminators and compensation discriminator,

(3) testing the characteristics, including compensation, of the test modulators and broad-band discriminators,

(4) testing the broad-band system employing the Sony TC-126 to record and playback the test signals,

(5) testing the hybrid system (15/80 record speed and 15/16 playback speed) employing the P.I. 5100 5-day recorder as the record machine and the $\mathrm{B} \& \mathrm{H}-3700 \mathrm{~B}$ as the playback machine。

The work on the discriminators was actually carried out first because they appeared to pose the most serious limitations on the systems. Several combinations of center frequencies, deviations, discriminator input bandpass filters and output low-pass filters, and compensation discriminator input band-pass filters were tried. In these notes only the final (most successful) version will be described. The order of presentation was chosen for clarity and simplicity, not to suggest the order in which various parts of the work were accomplished. II. Broad-band Multiplex System Design, Components, and Tests

a. Subcarrier frequencies and deviations.

The layout of channels for the standard (30 hz) NCER multiplex system, for the broad-band (150 hz) NCER multiplex system, and for the hybrid 5-day tape system adaptation $(30 \mathrm{hz}$ ) of the broad-band multiplex system is illustrated in Figure la. In the standard system, there are 8 data channels, with center frequencies of $340(I+N) h z$, where $N$ is the channel number, and maximum deviations of $\pm 125 \mathrm{hz}$. A special timing channel with a center frequency of $3700 \mathrm{hz}$ has a maximum deviation of $\pm 100 \mathrm{hz}$ in the modulator, but the discriminator input bandpass filter has a width of 
$\pm 200 \mathrm{hz}$ to enhance the high frequency response of the channel. The compensation reference frequency, $4688 \mathrm{hz}$, is unmodulated and is played back through a compensation discriminator with an input bandpass filter with a bandwidth of $\pm 200 \mathrm{hz}$.

In the broad-band system there are 4 data channels (including timing) with center frequencies of $680(1+N) h z$ where $N$ is the channel number, and deviations of $\pm 200 \mathrm{hz}$. The compensation reference frequency, $4688 \mathrm{hz}$, is unmodulated and is played back through a compensation discriminator with an input bandpass filter bandwidth of $\pm 500 \mathrm{hz}$.

The four channels in the hybrid system have "record" center frequencies of $136(1+\mathrm{N}) \mathrm{hz}$, where $\mathrm{N}$ is the channel number, and deviations of $\pm 40 \mathrm{hz}$. The unmodulated compensation reference frequency is $938 \mathrm{hz}$. When speeded up 5 times on playback, the hybrid system is transformed into the broadband system. Data frequencies are also increased by a factor of 5, however" so the $150 \mathrm{hz}$ upper limit of the broad-band playback system restricts data frequencies in the hybrid system to $30 \mathrm{hz}$ 。

b. Test modulators

The test VCO bank built for the broad-band and hybrid systems is illustrated in Figure 1b. Modulators with the required center frequencies and deviation sensitivities are provided for all 10 subcarriers of the combined systems. Any desired combination of subcarriers can be switched into the summing amplifier and combined to form the multiplexed output signal. Two different modulation modes are available by a separate modulation control switch on each modulator. The equal offset modulation option deviates each channel the same number of $\mathrm{hz}: \pm 200 \mathrm{hz}$ for the broad-band system and $\pm 40 \mathrm{hz}$ for the hybrid system, when the modulating 
voltage is $\pm 3,00$ volts. The proportional offset modulation option deviates each channel an amount that is proportional to its center frequency: $\delta F_{C i}= \pm 200 \times \frac{F C i}{3125} h z$ for a modulating voltage of \pm 3.00 volts. For both options deviation is proportional to the modulating voltage; so precise modulation levels of lower value can be obtained by scaling down the modulating voltage (e.g. with the calibrated attenuator on the Wavetek model 142 signal generator).

The equal deviation modulation mode is convenient for running system response and dynamic range tests. The proportional deviation modulation mode can be used to synthesize the effects of tape speed variations in order to facilitate adjusting compensation input levels on the data discriminators and testing the effectiveness of compensation as a function of frequency.

\section{c. Discriminators}

A set of broad-band discriminators was obtained by modifying the model 6203 Develco discriminators used in the standard NCER multiplex system. Three changes were required: 1) raise the cutoff frequency of the discriminator low-pass output filter from $30 \mathrm{hz}$ to $150 \mathrm{hz}, 2$ ) raise the cutoff frequency of the low-pass ripple suppression filter in the discriminator amplifier feed-back circuit, and 3) broaden the width of the input bandpass filter. The manufacturer (Develco) had faced a similar problem in the construction of a compensation discriminator by modification of a standard data discriminator. By comparing the circuits of the standard data discriminators and the compensation discriminator it was possible to identify the components that had to be changed. The following list of 
of substitutions for the compensation discriminator and the broad-band data discriminators refers to Figure 7, page 18, of the Develco manual "Instruction and Service Manual, Model 6203 Discriminator, Revision B, June 1969".

\begin{tabular}{|c|c|c|c|c|}
\hline Component & Std. Data Discr. & Comp. Discr. & Broad-band I & Data \\
\hline $\mathrm{C} 16$ & $0.033 \mu \mathrm{F}$ & $0.0027 \mu \mathrm{F}$ & $0.0082 \mu \mathrm{F}$ & \\
\hline R52 & $11 \mathrm{M}$ & $910 \mathrm{~K}$ & $1.8 \mathrm{M}$ & \\
\hline R53 & $5.1 \mathrm{M}$ & $430 \mathrm{~K}$ & $860 \mathrm{~K}$ & \\
\hline R54 & $2.7 \mathrm{M}$ & $220 \mathrm{~K}$ & $440 \mathrm{~K}$ & \\
\hline R55 & $5.1 \mathrm{M}$ & $430 \mathrm{~K}$ & $860 \mathrm{~K}$ & \\
\hline R56 & $11 \mathrm{M}$ & $910 \mathrm{~K}$ & $1.8 \mathrm{M}$ & \\
\hline R57 & $3 \mathrm{M}$ & $240 \mathrm{~K}$ & $480 \mathrm{~K}$ & \\
\hline R59 & $1.2 \mathrm{M}$ & $100 \mathrm{~K}$ & $200 \mathrm{~K}$ & \\
\hline R60 & $4.7 \mathrm{M}$ & $390 \mathrm{~K}$ & $780 \mathrm{~K}$ & \\
\hline R63 & $15 \mathrm{M}$ & $1.2 \mathrm{M}$ & $2.4 \mathrm{M}$ & \\
\hline R64 & $10 \mathrm{M}$ & $820 \mathrm{~K}$ & $1.6 \mathrm{M}$ & \\
\hline R65 & $2.4 \mathrm{M}$ & $200 \mathrm{~K}$ & $400 \mathrm{~K}$ & \\
\hline R66 & $1.2 \mathrm{M}$ & $100 \mathrm{~K}$ & $200 \mathrm{~K}$ & \\
\hline R67 & $2.4 \mathrm{M}$ & $200 \mathrm{~K}$ & $400 \mathrm{~K}$ & \\
\hline R68 & $10 \mathrm{M}$ & $820 \mathrm{~K}$ & $1.6 \mathrm{M}$ & \\
\hline R69 & $1.8 \mathrm{M}$ & $150 \mathrm{~K}$ & $300 \mathrm{~K}$ & \\
\hline R72 & $1 \mathrm{M}$ & $82 \mathrm{~K}$ & $164 \mathrm{~K}$ & \\
\hline R73 & $3.9 \mathrm{M}$ & $330 \mathrm{~K}$ & $660 \mathrm{~K}$ & \\
\hline R75 & $20 \mathrm{M}$ & $1.6 \mathrm{M}$ & $3.2 \mathrm{M}$ & \\
\hline R76, R78, 8 & & Delete & & \\
\hline R77 & $100 \mathrm{~K}$ & $33 \mathrm{~K}$ & $100 \mathrm{~K}$ & \\
\hline R78 & & $100 \mathrm{~K}$ & $10 \mathrm{~V}$ and $\mathrm{B}$ & \\
\hline
\end{tabular}


These changes raise the low-pass cut-off frequency from about 30 hz for the standard data discriminator to about $150 \mathrm{hz}$ for the broad-band data discriminator and to about $300 \mathrm{hz}$ for the compensation discriminator (and reverse its output polarity, as well). It was also found to be desirable to change Cl4 from $4700 \mathrm{pF}$ to $1000 \mathrm{pF}$ for the $4688 \mathrm{hz}$ compensation discriminator and the $3400 \mathrm{hz}$ broad-band data discriminator. It was also necessary to select a new value for R32 to achieve zero output for the undeviated center frequency and to adjust R26 and R27 to establish a voltage at the source of Q18 that would insure undistorted operation of the compensation circuit for a large compensation input signal. A $20 \mathrm{~K}$ resistor was also put in series with $\mathrm{R} 24$, the compensation input level adjustment potentiometer, to densensitize this potentiometer to permit more precise adjustment.

The input band-pass filters were adjusted to the appropriate center frequencies and band widths by appropriate changes in the values of Cl, C2, C3, C4, C5, and C6 and very careful adjustment of L1, L2, and L 3 . It was also helpful to adjust R3 to provide proper loading on the filter and to shunt L2 with an appropriate resistor ( $4 \mathrm{~K}$ to $10 \mathrm{~K}$, by trial and error) to flatten the central portion of the final band-pass filter response curve. Broadening the input band-pass filters resulted in a substantial reduction in the overall sensitivity of the discriminators. They require input signals in which their subcarriers are at a level of several hundred millivolts peak to peak for reliable operation. The input filters for the broad-band data discriminators are down 3 db at $\pm 180 \mathrm{hz}$ and about $4.5 \mathrm{db}$ at $\pm 200 \mathrm{hz}$. The input filter of the $4688 \mathrm{hz} \mathrm{compen}-$ sation discriminator is down about $1.5 \mathrm{db}$ at $\pm 500 \mathrm{hz}$ and about $20 \mathrm{db}$ at $\pm 900 \mathrm{hz}$ The low-pass output filters of the broad-band discriminators fall off to $70 \%$ maximum response at $100 \mathrm{hz}$ and to $50 \%$ maximum response at $150 \mathrm{hz}$. 


\section{d. Modulator/discriminator compensation tests}

The broad-band data and compensation modulators were driven by a $10 \mathrm{hz}$ square wave and a 10 to $300 \mathrm{hz}$ swept frequency sine wave in the proportional deviation mode at a modulation level of - $10 \mathrm{db}(32 \%)$. The resulting multiplex signal was detected by the broad-band discriminators, with compensation, and played out on the Siemens Oscillomink at a paper speed of $100 \mathrm{~mm} / \mathrm{sec}$. On Figure 2 the upper four (data channel) traces were played out with an oscillomink sensitivity of $5 \mathrm{mv} / \mathrm{mm}$ and the bottom trace (compensation channel output), with a sensitivity of $125 \mathrm{mv} / \mathrm{mm}$. The data discriminator compensation input potentiometers had been adjusted to minimize the compensated output for the square wave modulating signal. For the swept sine wave, reduction of the "error" signal was $25 \mathrm{db}$ or better on all channels for frequencies below $100 \mathrm{hz}$, and $22 \mathrm{db}$ or better for frequencies below $150 \mathrm{hz}$.

e. Modulator/discriminator noise test

A $2 \mathrm{hz}$ square wave at modulation levels of $0 \mathrm{db}$ (100\%), - $10 \mathrm{db}, ' \mathrm{\prime}$. $-60 \mathrm{db}(0.1 \%)$ was impressed on all four data channels, detected by the broad-band discriminators with the compensation discriminator in operation (on all but the last 2 tests), and played out at a paper speed of $25 \mathrm{~mm} / \mathrm{sec}$ on the Oscillomink. These tests are illustrated Figure 3.

With the compensation discriminator functioning, the noise level is $50 \mathrm{db}$ or more below maximum modulation output levels on all data channels, and it approaches $-60 \mathrm{db}$ on channels 3 and 4 . The high frequency noise on channels 1 and 2 appears to result from interaction of the $4688 \mathrm{hz}$ 
ripple in the compensation discriminator output and the channel 1 and channel 2 subcarriers. This noise disappears when the compensation discriminator is unplugged, even though the compensation subcarrier is still included in the multiplex signal.

f. Modulator/discriminator system response tests

A $10 \mathrm{hz}$ to $200 \mathrm{hz}$ swept frequency sine wave at modulation levels of $100 \%, 10 \%$, and $1 \%$ was imposed on the modulators, detected by the broad-band discriminators, and played out on the Oscillomink at a paper speed of $100 \mathrm{~mm} / \mathrm{sec}$. These tests are illustrated in Figure 4. For strong modulation, e.g. 100\% (Figure 4a) and 10\% (Figure 4b), the signal was well above noise levels at all frequencies. At the 1\% modulation level, interference between the high frequency noise on channels 1 and 2 and the sine wave signal produced serious distortion (beats, etc.) in the output signal at high frequencies (Figure 4C). With the compensation discriminator removed (Figure 4d), this interference disappeared and the $1 \%$ modulation level produced clear signals at frequencies as high as $200 \mathrm{hz}$.

g. Crosstalk tests

Each channel in turn was modulated at the 100\% level by $1 \mathrm{hz}$ and $10 \mathrm{hz}$ square waves and by a $10 \mathrm{hz}$ to $300 \mathrm{hz}$ swept frequency sine wave while all other channels were left unmodulated. The multiplex signal from the modulator bank was fed directly to the broad-band discriminators and the discriminated signals were recorded at appropriate sensitivities on the Oscillomink at a paper speed of $25 \mathrm{~mm} / \mathrm{sec}$. The compensation discriminator was operating in every test. Results of these tests are shown in Figure 5. Crosstalk on adjacent channels is appreciable for signals with very rapid changes in amplitude, such as the square waves and high frequency ( $100+\mathrm{hz})$ sine waves. 
The effect of channel 1 on other channels, even channel 2, is minimal. The strongest crosstalk is from channel 2 to channel 1 , suggesting that channel I should be dedicated to timing signals at modulation levels of 25\% to $75 \%$. Crosstalk among channels 2, 3, and 4 generally is below $1 \%$ $(-40 \mathrm{db})$ for sine wave frequencies of $150 \mathrm{hz}$ and less.

III. Broad-band System Recorded and Played Back on the Sony TC-126 Cassette Recorder a. Sony TC-126 cassette recorder

This recorder is a small inexpensive consumer type two track AM stero cassette tape recorder that is being considered for use in a light-weight portable seismic refraction system. Using iron oxide tape, the response of the system to signals recorded and played back through the "Iine" input/output terminals is flat between $500 \mathrm{hz}$ and $1 \mathrm{~K} \mathrm{hz}$ and falls off to about $40 \%$ at $100 \mathrm{hz}$ and $6 \mathrm{khz}$. Better high frequency response can be obtained using chromium oxide tape; but the standard iron oxide tape was used in these tests.

To establish an optimum recording level the multiplexed signal was introduced to the recorder and recovered from the tape monitor output (without recording and playing back from tape). Both the input and output signals were displayed on a 2 track oscilloscope. For input levels of $300 \mathrm{mv} p-\mathrm{p}$ or less, the output signal appeared to be undistorted and its level was linearly dependent on the input level.

Next the tape monitor signal was introduced to a broad-band discriminator and its output was displayed on the scope along with the multiplex input signal. As the input signal was increased progressively above $300 \mathrm{mv} \mathrm{p}-\mathrm{p}$ the discriminator output noise level also increased steadily. There was little variation in that noise level for input signals between $150 \mathrm{mv} \mathrm{p}-\mathrm{p}$ and $300 \mathrm{mv} \mathrm{p}-\mathrm{p}$, however. Examination of the noise generated by large 
input signals suggested strongly that "clipping" of peaks or troughs from the complex multiplex signal was the cause of the noise that appeared on the discriminator output. In the tests that follow, input signal levels were limited to $300 \mathrm{mv}$ p-p.

The tape recorder employs an automatic gain control circuit, but the effect of that circuit was minimized by the low input signal levels used in these tests. The AGC circuit was not adjusted to avoid distortion of the multiplex signal when oversized input signals were applied. b. Noise levels (dynamic range) of the broad-band system recorded and played back on the sony

A $2 \mathrm{hz}$ square wave signal at modulation levels of $0 \mathrm{db}$ (100\%) -10 db, ''' - $60 \mathrm{db}(0.1 \%)$ was impressed on the four data channels of the modulator bank and the resulting multiplex signal was recorded on the Sony recorder. The tape was then played back through the Sony, discriminated by the set of broad-band discriminators, with compensation, and played out at a paper speed of $25 \mathrm{~mm} / \mathrm{sec}$ on the Oscillomink (Figure 6a). The compensation output was recorded at a sensitivity of $50 \mathrm{mv} / \mathrm{mm}$ throughout, but the data channel sensitivities were varied to obtain clear records. By reference to the $-40 \mathrm{db}$ modulation level test, it is apparent that the output noise level on the data channels, with compensation, is near the $-40 \mathrm{db}$ level. The experiment was repeated with the channel 4 subcarrier turned off (Figure 6b). There is a clear reduction in the noise on the remaining 3 channels; and channels 2 and 3 have noise levels somewhat lower than $-40 \mathrm{db}$.

C. Crosstalk and system frequency response Each data subcarrier in turn was modulated at the $100 \%$ level by a $10 \mathrm{hz}$ square wave and a $10 \mathrm{hz}$ to $300 \mathrm{hz}$ swept frequency sine wave while all other 
subcarriers were left unmodulated. After recording and playback on the discriminated by the broad-band discriminators and Sony the resulting multiplex signals were/played out on the Oscillomink at a paper speed of $25 \mathrm{~mm} / \mathrm{sec}$. The modulated channel was played out at a sensitivity of $125 \mathrm{mv} / \mathrm{mm}$, the compensation channel at $50 \mathrm{mv} / \mathrm{mm}$, and the unmodulated data channels at $5 \mathrm{mv} / \mathrm{mm}$. These tests (Figure-7) illustrate the frequency response of the system as well as crosstalk between channels. For frequencies of $150 \mathrm{hz}$ and less; crosstalk is generally low. The most serious case is contamination of channel 1 by channel 2 at frequencies of $150 \mathrm{hz}$ and up.

d. Effectiveness of compensation

A $2 \mathrm{hz}$ square wave at modulation levels of $0 \mathrm{db}$ (100\%) to - $60 \mathrm{db}(0.1 \%)$ was impressed on the 4 data channel modulators and recorded on the sony. On playback through the broad-band discriminators onto the Oscillomink at a paper speed of $10 \mathrm{~mm} / \mathrm{sec}$, sections of record with compensation and without compensation were obtained for each modulation level (Figure 8a, 8b). Without compensation the noise level ranged from about - $20 \mathrm{db}$ on channel 4 to - $30 \mathrm{db}$ on channel 1. With compensation, the noise level was about - $40 \mathrm{db}$ on all channels.

The experiment was repeated with the channel 4 subcarrier deleted (Figure 8c). Results were similar to those above, except for a small reduction in the "compensated" noise levels on the remaining channels. e. Channel usage, and elimination of channels.

Because of its somewhat higher noise level and greater susceptibility to crosstalk, channel 1 should be reserved for timing signals recorded at high modulation levels (25\% to 75\%). If fewer than 3 data channels are required, elimination of channel 4 diminishes the noise levels on channels 2 and 3 by a small amount. 
IV. Hybrid system employing the P.I. 5100 5-day tape recorder

a. P.I. 5100 tape recorder, test modulators, and playback system

The P.I. 5100 tape recorder is a low power portable 1/2" machine with stacked 14" reels. It was originally set up to record 7 channels of FM data ( $84.4 \mathrm{hz}$ center frequency, $40 \%$ modulation) and to run for 10 days on a 14" reel of tape at 15/160 ips. The upper limit of data frequency was about $17 \mathrm{hz}$, and as operated by the Survey, the dynamic range of the recorder was $30 \mathrm{db}$ or somewhat less. The seismic system employing these recorders is being refurbished:

(1) the tape is being speeded up to 15/80 ips (5 days/14" reel),

(2) the FM channel center frequency is being quadrupled ( $337.5 \mathrm{hz})$,

(3) the seismic amplifiers and modulators (originally part of the recorder) are being replaced by NCER-built low power electronics,

(4) the upper limit of data frequencies will be about $50 \mathrm{hz}$ or higher

(5) the new system will run for 5 days on a 60 amp-hour car battery,

(6) a multiplex timing/compensation channel is being used so that 6 channels can be used for seismic data,

(7) the dynamic range of the new system's FM channels will be about $40 \mathrm{db}$.

For the purpose of these tests to establish the applicability of FM subcarrier multiplex recording in the a.m. mode on the P.I. 5100, the tape recorder heads were driven by the summing amplifier in the test VCO bank. A $9 \mathrm{~K} \mathrm{hz}$ bias signal was added to the multiplex data and compensation track subcarriers in the test VCO bank summing amplifier, also.

The test modulators used in these tests are the ones designated by primes on Figure lb (272 hz, $408 \mathrm{hz}, 544 \mathrm{hz}, 680 \mathrm{hz}$, and $938 \mathrm{hz})$. 
The tapes were played back at 15/16 ips on the B \& H 3700B reproduce machine and the multiplex signal recovered from the $B$ \& $H$ direct reproduce amplifiers was fed to the broad-band discriminator bank for playout. b. Bias and modulation level tests

In AM recording the "data" signal to be recorded is added to a much higher frequency, larger amplitude, bias signal to suppress effects of hysteresis that are encountered in recording on magnetic tape. The quality of the signal that can be recovered from tape is critically dependent on the amplitude levels of the bias and data signals. Accordingly, a series of tests was carried out with the P.I. 5100 operating at a tape speed of 15/80 ips to determine optimum values for the bias and data signal amplitude levels.

The DC resistance of the recording head is about $10 \mathrm{ohms}$, and a $10 \mathrm{ohm}$ head current monitoring resistor was placed in series with the head. The head and head current monitoring resistor were driven by the summing amplifier in the test modulator bank, which has an output resistance of about 600 ohms. A $9 \mathrm{~K}$ hz sine wave bias signal was provided by a signal generator with adjustable output level and was combined with the multiplex signal in the test modulator bank summing amplifier. Adjustment of the summing amplifier gain thus affected both the multiplexed data/compensation and bias signal levels; and the ratio of the multiplexed data/compensation signal and the bias signal could be controlled independently by the bias signal generator output level. The bias and multiplexed data/compensation signals were measured as voltages at the output of the summing amplifier that drove the head and its 10 ohm series resistor. 
Tests were carried out for multiplexed data/compensation signal peak to peak voltages of $7.5 \mathrm{mv}, 10 \mathrm{mv}, 12.5 \mathrm{mv}$, $15 \mathrm{mv}, 17.5 \mathrm{mv}, 20 \mathrm{mv}$, and $30 \mathrm{mv}$, each recorded with bias signal peak to peak voltages of $0.9 \mathrm{~V}, 1.1 \mathrm{~V}, 1.25 \mathrm{~V}$, $1.4 \mathrm{~V}$ and $1.6 \mathrm{~V}$. Results from the tests at data/compensation signal levels of $12.5 \mathrm{mv}$ and $15 \mathrm{mv}$ were clearly superior to those with higher and lower values of this parameter. The effect of varying the bias signal level for these two values of data/compensation signal level is shown in Figure 9. The best results (Figure 9b) were a data/compensation signal level of $15 \mathrm{mv}$ and a bias signal level of $1.25 \mathrm{~V}$. These values were adopted for further tests of the system.

Because head current is a function of frequency as well as voltage, it would have been better to monitor the bias and data/compensation head currents by monitoring voltages across the $10 \mathrm{ohm}$ resistor in series with the head rather than by monitoring the voltages at the output of the head driver amplifier.

To evaluate the effectiveness and frequency dependence of subtractive compensation in the hybrid system, an appropriately modulated tape was recorded (at 15/80 ips) on the P.I. 5100, played back (at 15/16 ips) on the $\mathrm{B} \& \mathrm{H} 3700 \mathrm{~B}$, discriminated by the broad-band discriminators with compensation, and played out on the Oscillomink at a paper speed of $100 \mathrm{~mm} / \mathrm{sec}$. The recorded signal consisted of a $1 \mathrm{hz}$ to $50 \mathrm{hz}$ swept frequency sine wave imposed in the proportional deviation modulation mode on the 5 reduced frequency channels (4 data and I compensation reduced frequency VCO's). The results of the test are shown in Figure 10: the upper 4 traces are the compensated data channels played out at a sensitivity of $12.5 \mathrm{mv} / \mathrm{mm}$, the 5 th trace is the compensation channel at $50 \mathrm{mv} / \mathrm{mm}$, and the bottom trace 
is the output of an uncompensated FM channel modulated in the same manner as the compensation channel and played out through a $125 \mathrm{hz}$ (25 hz data frequency) Krohn-Hite filter at a sensitivity of $50 \mathrm{mv} / \mathrm{mm}$.

In this test subtractive compensation is acting to eliminate noise produced by real tape speed variations as well as the simulated tape speed variations generated by the proportional deviation mode modulation.

On data channel 1 the synthetic tape speed variation signal was reduced by at least $19 \mathrm{db}$ from $1 \mathrm{hz}$ to $30 \mathrm{hz}$. On channel 2 the reduction was at least $19 \mathrm{db}$ at frequencies of $20 \mathrm{hz}$ and less and $16 \mathrm{db}$ at $30 \mathrm{hz}$. Channel 3 showed the poorest results: the reduction was at least $19 \mathrm{db}$ at frequencies of $10 \mathrm{hz}$ and less but decreased to $15 \mathrm{db}$ at $20 \mathrm{hz}$ and $13 \mathrm{db}$ at $30 \mathrm{hz}$. On channel 4, the reduction of the synthetic tape speed variation signal was greater than $20 \mathrm{db}$ from $\mathrm{l} \mathrm{hz}$ to $30 \mathrm{hz}$.

d. FM channel output noise level versus output filter cutoff frequency To permit comparison of signals recovered from the compensated multiplexed data channels with that available from the "new standard" 5-day tape system FM data channels, one FM channel was modulated directly at the same level and by the same signal as the multiplexed channels. On playback, the output of the FM channel was passed through an adjustable low pass filter (Krohn-Hite) before recording on the Oscillomink. In Figure 11 the multiplexed and the FM channels are compared for a number of FM channel low-pass filter settings The signal recorded on all channels was a $1 / 2 \mathrm{hz}$ square wave at the - $30 \mathrm{db}$ modulation level. The Krohn-Hite filter settings and the corresponding data cutoff frequencies are indicated above $(\mathrm{K}-\mathrm{H})$ and below (data) the portions of the FM channel playback to which they apply. The output noise level increases with increasing cutoff frequency, but it it is relatively constant, and about equal to the noise on the multiplexed 
channels, between data cutoff frequencies of 25 and $40 \mathrm{hz}$, For this range of cutoff frequencies, the output noise on the FM channel is about $40 \mathrm{db}$ below the output for full modulation.

e. Noise (dynamic range) tests of the hybrid system

To evaluate the dynamic range of the hybrid system, 1/2 hz square waves at modulation levels of $-20 \mathrm{db}(10 \%),-30 \mathrm{db},-40 \mathrm{db}$, and $-50 \mathrm{db}(0.32 \%)$ were recorded on the P.I. 5100, played back on the B \& H 3700B through the broadband discriminators, with compensation, and played out on the Oscillomink recorder at a paper speed of $25 \mathrm{~mm} / \mathrm{sec}$. Examination of Figure 12a, which illustrates these tests, shows that the noise level is about $50 \mathrm{db}$ below full modulation on all channels. Deletion of channel 4 (turning off its subcarrier) leads to a small reduction of noise on the other channels, particularly channels 2 and 3.

f. Hybrid system frequency response

To illustrate the frequency response of the hybrid system and to explore the dependence of signal to noise ratio on frequency, $1 \mathrm{hz}$ to $40 \mathrm{hz}$ swept frequency sine waves at modulation levels of $100 \%, 32 \%$, and $3.2 \%$ were recorded and played back through the system (Figures $13 a, b, c)$. The data cutoff frequency for the FM channel on Figure $13 \mathrm{~b}$ and Figure $13 \mathrm{c}$ was $25 \mathrm{hz}$.

The relative response of the multiplex data channels is approximately as follows:

$1 \mathrm{hz} \rightarrow 100 \%, 5 \mathrm{hz} \rightarrow 99 \%, 10 \mathrm{hz} \rightarrow 90 \%, 20 \mathrm{hz} \rightarrow 70 \%$, $30 \mathrm{hz} \rightarrow 45 \%, 50 \mathrm{hz} \rightarrow 10 \%$

9. Crosstalk in the hybrid system Signals consisting of $0.5 \mathrm{hz}$ and $5 \mathrm{hz}$ square waves and a $1 \mathrm{hz}$ to $100 \mathrm{hz}$ swept frequency sine wave were recorded at the $100 \%$ modulation level on each 
of the 4 multiplex data channels in turn while all other channels were left unmodulated. Playbacks of these tests are shown in Figure 14.

For sine wave modulation, crosstalk is minimal, Crosstalk on adjacent channels caused by square wave modulation ranged from about $40 \mathrm{mv}$ to $120 \mathrm{mv}$ peak to peak, i.e., from about - $40 \mathrm{db}$ to about - $30 \mathrm{db}$ relative to full modulation.

h. Compensation effectiveness in the hybrid system

To illustrate the effectiveness of compensation in removing noise generated by tape speed variation in the hybrid system, $1 / 2 \mathrm{hz}$ square wave signals at modulation levels of - $40 \mathrm{db}$ and - $50 \mathrm{db}$ were recorded on all 4 multiplex data channels and on the FM channel (with a $25 \mathrm{hz}$ data cutoff frequency). On playback, the multiplexed signals were played out both with compensation and without compensation at oscillomink paper speeds of $25 \mathrm{~mm} / \mathrm{sec}$ and $100 \mathrm{~mm} / \mathrm{sec}$ (Figure 15). From these tests it is evident that compensation has reduced the noise on the multiplex channels approximately as follows: channel $1 \rightarrow 7 \mathrm{db}$, channel $2 \rightarrow 10 \mathrm{db}$, channel $3 \rightarrow 11 \mathrm{db}$, channel $4 \rightarrow 13 \mathrm{db}$.

The noise level on the FM channel with the $25 \mathrm{hz}$ data cutoff frequency is very slightly lower than that on channels 2 and 3, and noticeably lower (perhaps $3 \mathrm{db}$ ) than that on channels 1 and 4.

i. Deletion of channels

Because of its greater susceptibility to crosstalk and somewhat elevated noise level, channel 1 should be devoted to timing signals recorded at moderately high modulation levels (e.g., 25 to 75\%).

The noise level on channel 4 is also somewhat higher than on channels 2 and 3; so channel 4 should be the first to be deleted if fewer than 3 data channels per track are required. 
Figure captions for "Notes on a Broad-band Variant of the NCER seismic Data Multiplex System for Use with Field Tape Recorders

Figure la channel layout of: 1) the standard NCER seismic multiplex system, 2) the broad-band variant of the NCER seismic multiplex system, and 3) the five-day-tape system adaption of the broad-band multiplex system. The last system is speeded up 5 times on playback so that it corresponds in subcarrier frequencies and deviations to the broad-band system.

Figure 1b Test VCO bank schematic for broad-band multiplex systems. Provides individual or multiplexed subcarriers of data and compensation channels. Modulation is d.c. coupled and can be in the form of either equal deviation of all subcarriers or deviation of each subcarrier in the same proportion of its center frequency. VCO bank is used to set up and test discriminators, including setting compensation input levels, and to test overall performance of the tape recording/tape reproducing system. 
Ltandand (30hz) NCER Muetiplet Lystem

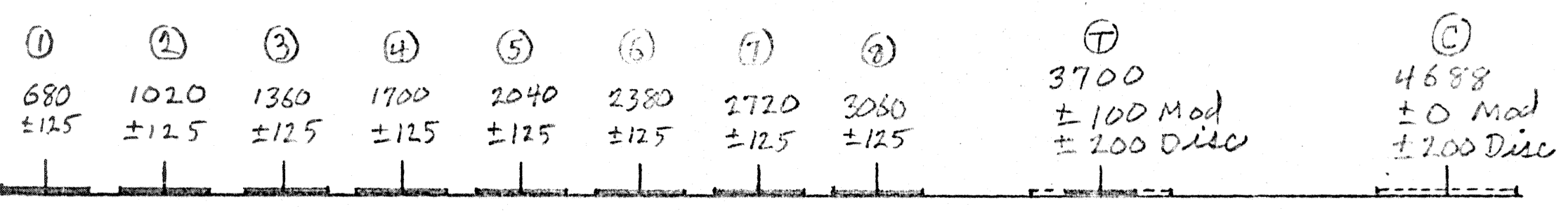

Broad-band (150hz) NCER Mulliplex bytem

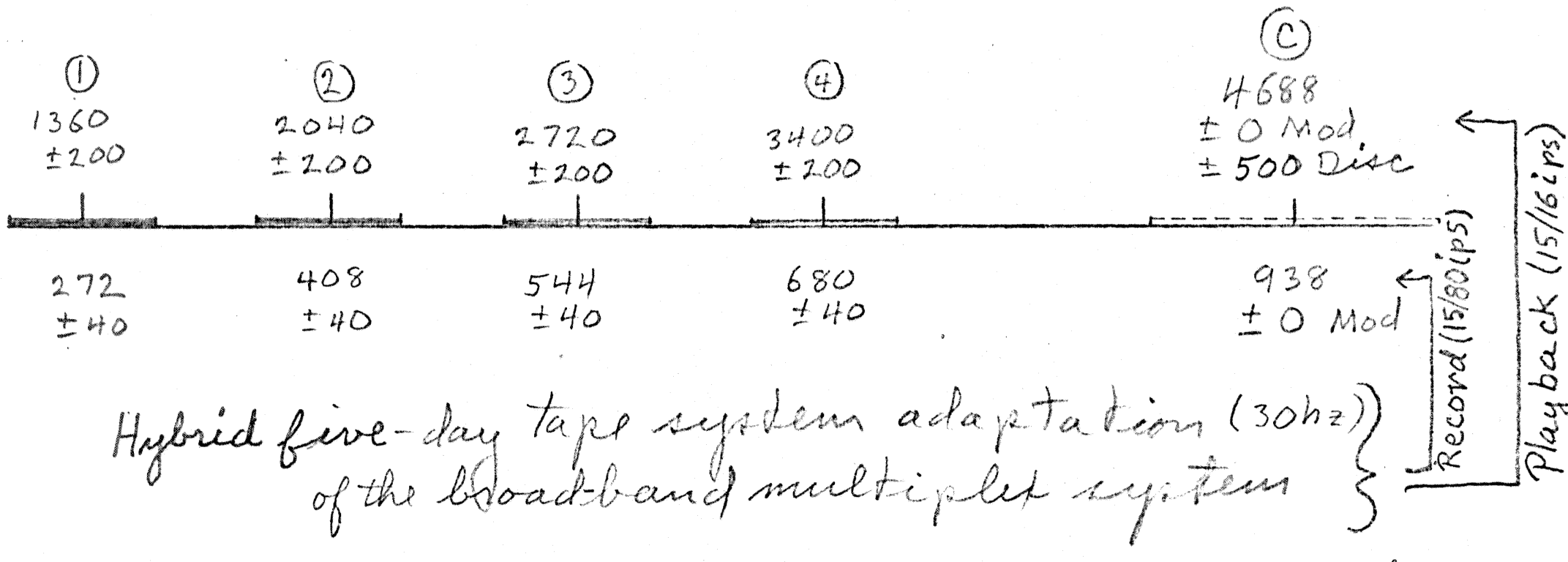

Fig $\mid a$ 


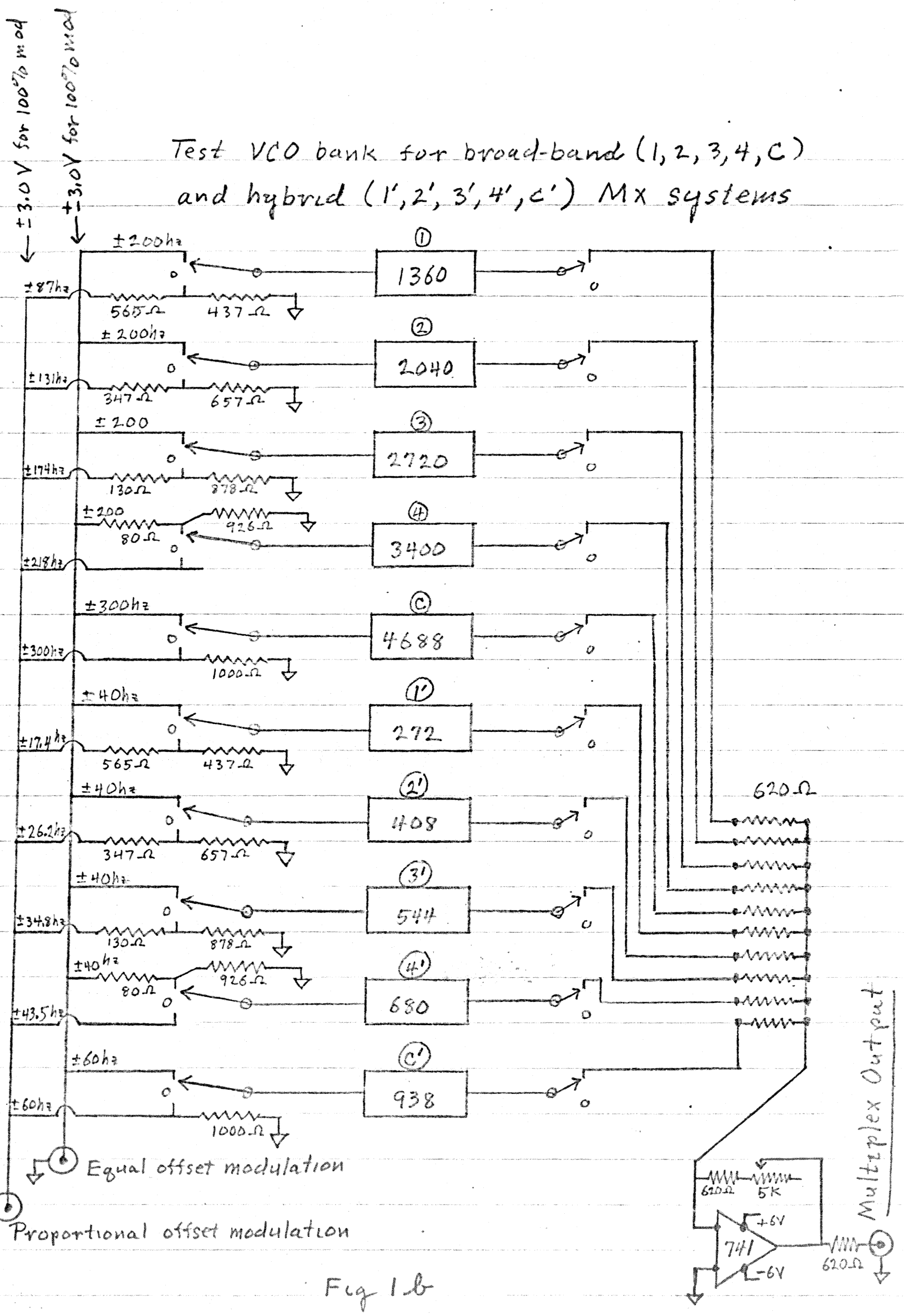


Figure 2 Compensation vs frequency test of the broad-band modulator/discriminator combination. Tape speed variation was simulated by deviating each carrier by an amount proportional to its center frequency. For the - $10 \mathrm{db}$ modulation level employed here, the deviation of channel $i$ is given by $\delta F_{C i}= \pm .316 \times 200 \times \frac{F_{C i}}{3125} \mathrm{hz}$, which corresponds to a tape speed variation of $\pm 2 \%$ The upper four traces show the compensated signals from channels 1 through 4 (at a sensitivity of $5 \mathrm{mv} / \mathrm{mm}$ ) and the 5 th trace shows the output of the compensation discriminator (at a sensitivity of $125 \mathrm{mv} / \mathrm{mm}$ ). The impressed signal (visible on the compensation channel) consisted of a $10 \mathrm{hz}$ square wave and a 10 to $300 \mathrm{hz}$ swept frequency sine wave. 


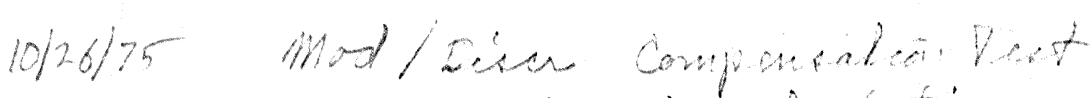

$-10 d b$ propintional modulation
-100 mm $/$ sec

(1) .1

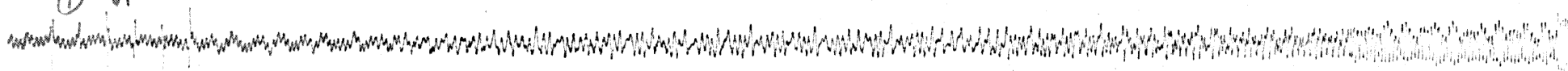

(2). 1

-

.4

(3) .1

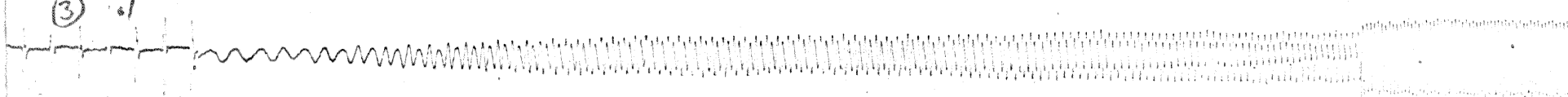

$\Theta .1$

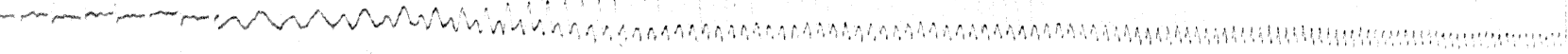

(c) 2.5

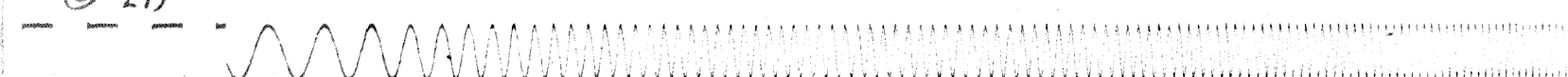

$-70 \mathrm{hz}-10 \mathrm{hz} \quad 50 \mathrm{hz} \quad 100 \mathrm{hz} \quad 150 \mathrm{hz} \quad 200 \mathrm{hz} \quad 300 \mathrm{hz}$

Fig 2


Figure 3 Noise (and dynamic range) tests of the broad-band modulator/discriminator combination. A $2 \mathrm{hz}$ square wave at modulation levels of $0 \mathrm{db}$ (100\%)

$-10 \mathrm{db},-20 \mathrm{db}, \cdots \cdot-60 \mathrm{db}(0.1 \%)$ was imposed on the data channel modulators, detected by the discriminators, and played out on the siemens Oscillomink. Removal of the compensation discriminator (but not the reference carrier) decreases the low-level noise on channels (1) and (2), as is shown in the 3rd strip from the right side of the figure. Playback of the - $60 \mathrm{db}$ modulation level at higher gain and higher speed with and without the compensation discriminator in operation as shown in the last two strips on the right, shows the noise to consist of regular sine waves with frequencies and levels of about $145 \mathrm{hz}$ at $-50 \mathrm{db}$ on channel 1 and $195 \mathrm{hz}$ at $-60 \mathrm{db}$ on channel 2.

Sensitivities at the various oscillomink settings are: $2.5 \rightarrow 125 \mathrm{mv} / \mathrm{mm}, 1.0 \rightarrow 50 \mathrm{mv} / \mathrm{mm}, .25 \rightarrow 12.5 \mathrm{mv} / \mathrm{mm}, .10 \rightarrow 5 \mathrm{mv} / \mathrm{mm}$ 


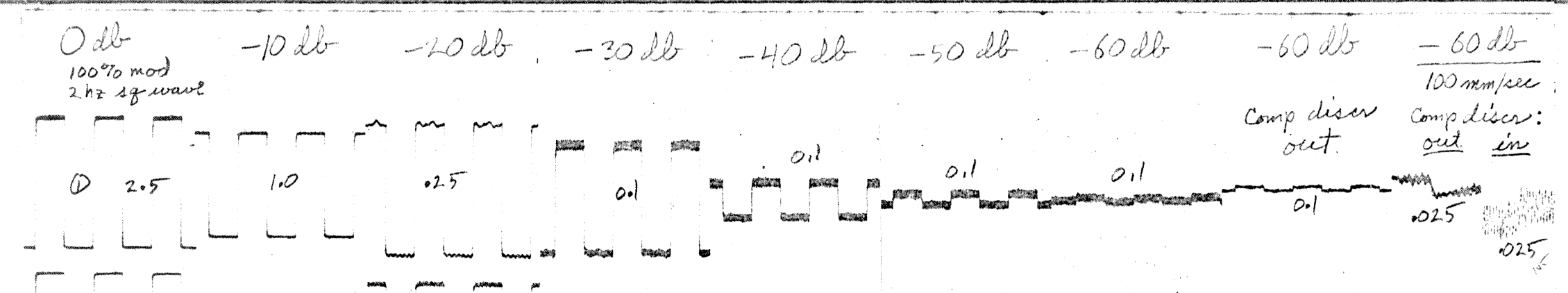

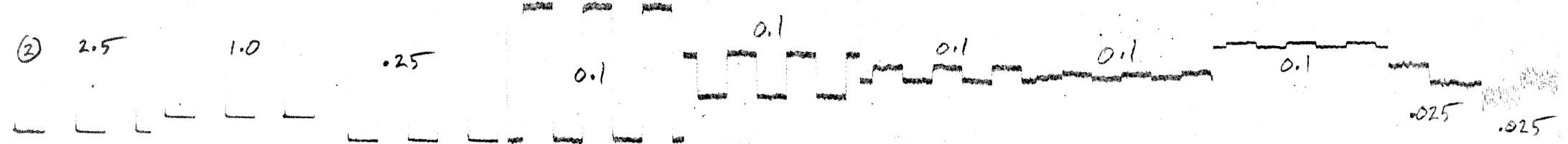

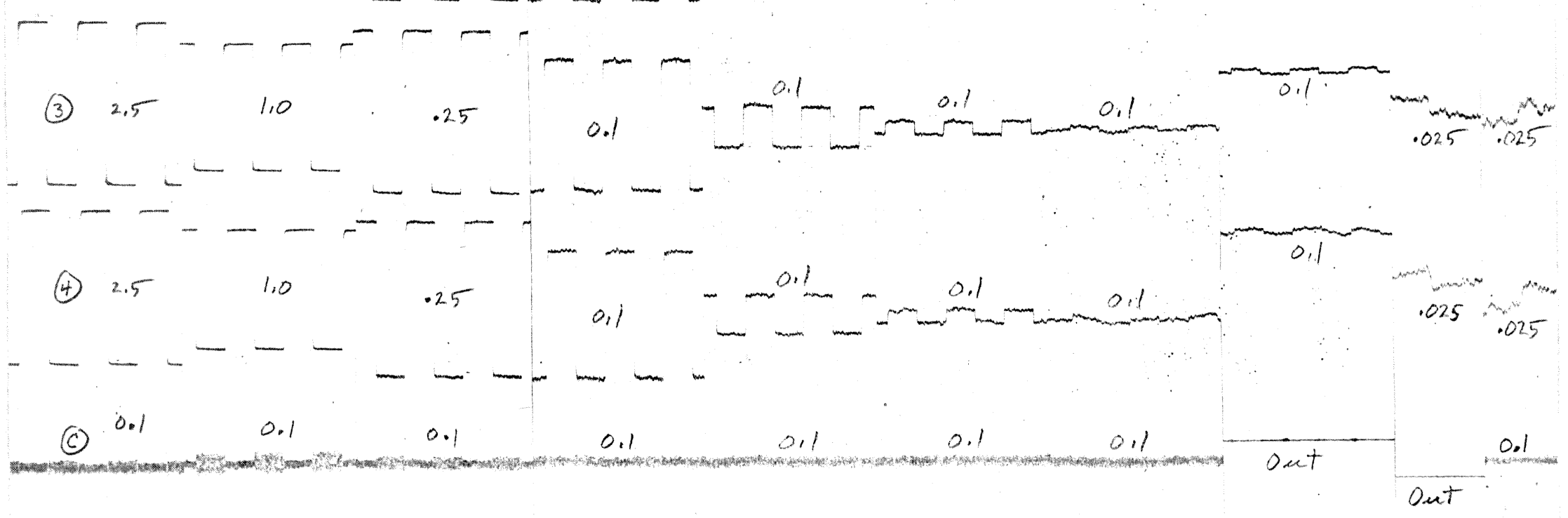

Moll Dis er noise and dynamic range test $10 / 27 / 75 \quad 25$ minter

Fig 3 
Figure 4 Frequency response of the broad-band modulator/discriminator combination demonstrated for various modulation levels, The outputs of all four data channel discriminators and of the reference channel (unmodulated) discriminator are shown. The Oscillomink sensitivities for the settings used were:

$$
\begin{aligned}
& 2.5 \rightarrow 125 \mathrm{mv} / \mathrm{mm} ; 1.0 \rightarrow 50 \mathrm{mv} / \mathrm{mm} ; .25 \rightarrow 12.5 \mathrm{mv} / \mathrm{mm} ; \\
& .10 \rightarrow 5 \mathrm{mv} / \mathrm{mm}
\end{aligned}
$$

a. Modulation level $0 \mathrm{db}$ (100\%)

b. Modulation level - $20 \mathrm{db}(10 \%)$

c. Modulation level $-40 \mathrm{db}$ (1\%)

Note the amplitude modulation of the channel (1) signal at $200 \mathrm{hz}$ resulting from the noise (at about 145 and $196 \mathrm{hz}$, respectively) introduced to these channels through the compensation discriminator.

d. Modulation level - $40 \mathrm{db}(1 \%)$, but with compensation discriminator removed. Note the disappearance of the "beat" phenomenon described in "c", above. 
$10 \mathrm{hz}$ $50 \mathrm{hz}$
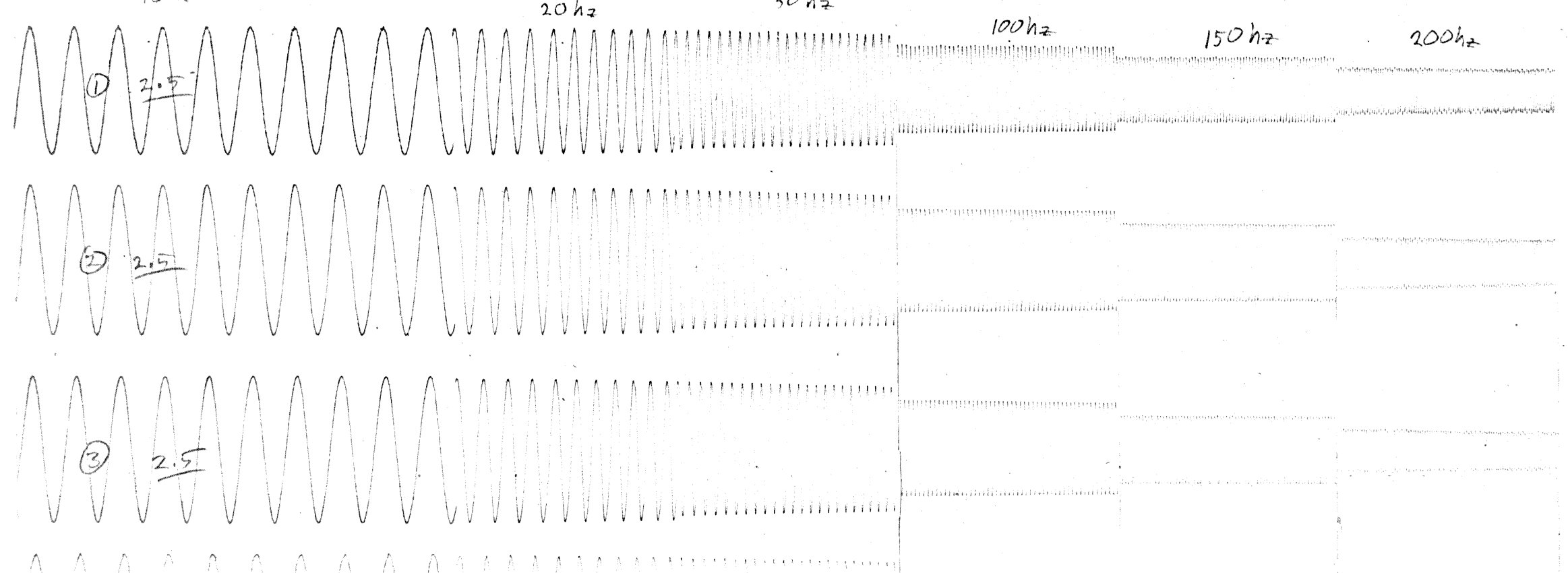

(4) 2,5

(C).10

\section{Fig $4 a$}

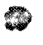




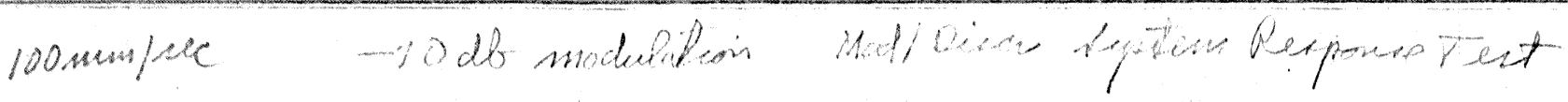
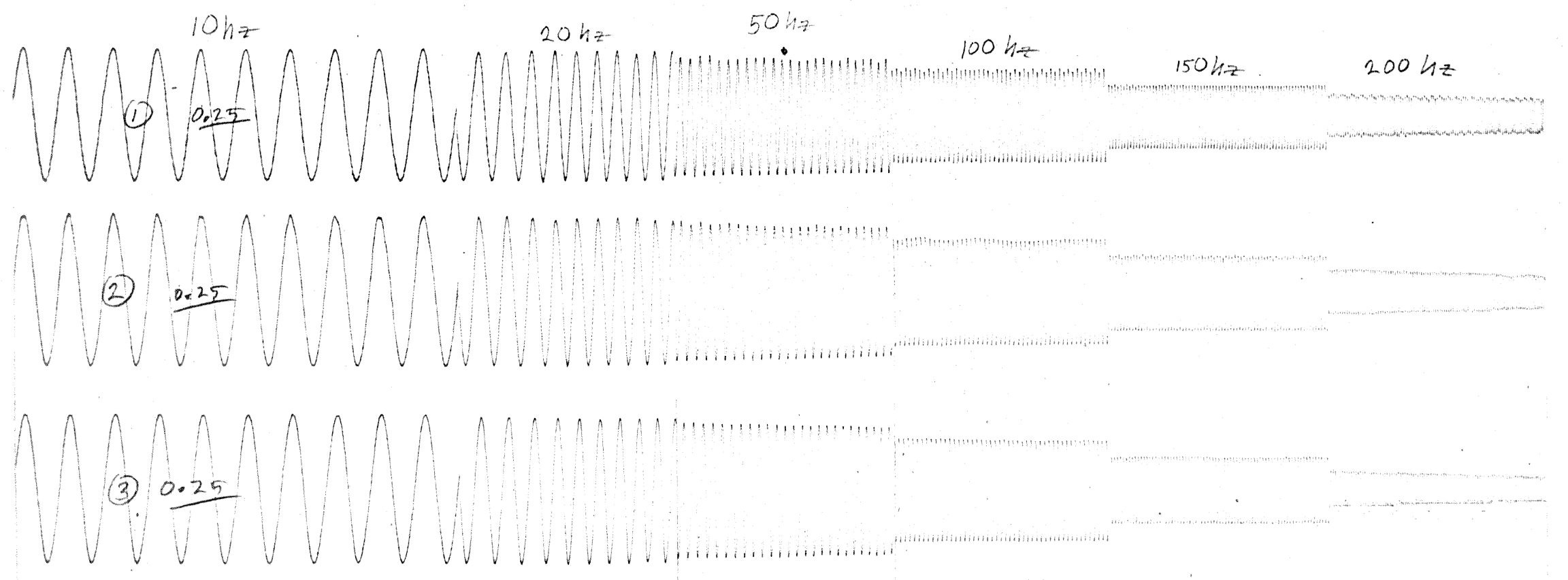

(4) 0.25

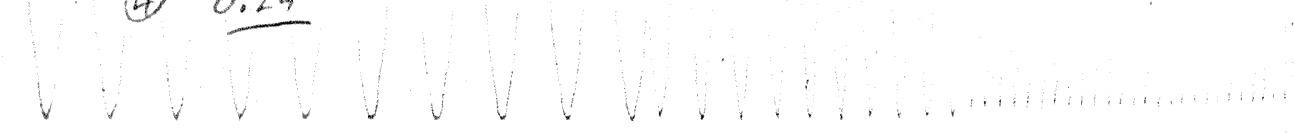

(c) 0.1

Feg $4 b$

6

* 


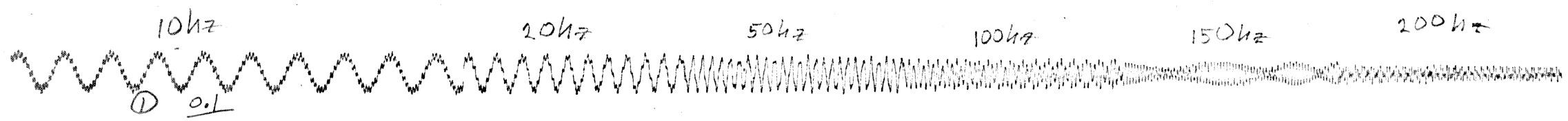

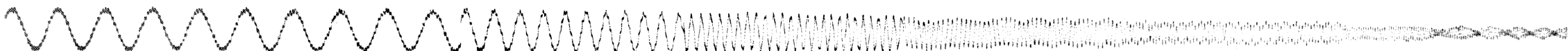
(2) 0.1

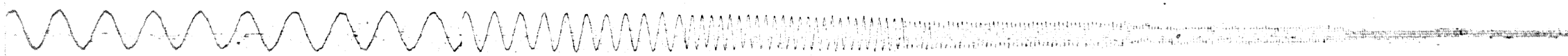
(3) 0.1

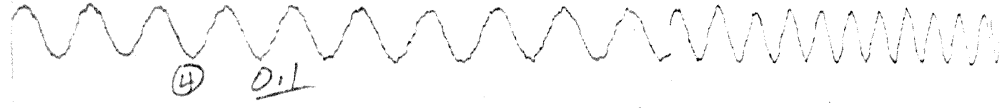

(c) 0,1

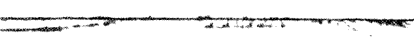

\section{Fig $4 C$}



Figure 5 Crosstalk tests of the broad-band modulator/discriminator combination. On each test one data channel was modulated at the 0 db level (100\%) by $1 \mathrm{hz}$ and $10 \mathrm{hz}$ square waves and by a $10 \mathrm{hz}$ to $300 \mathrm{hz}$ swept frequency sine wave. The discriminator output of the modulated channel was recorded on the oscillomink at a sensitivity of $125 \mathrm{mv} / \mathrm{mm}$ and the outputs of the other data channels and the compensation channel (all unmodulated) were recorded at a sensitivity of $5 \mathrm{mv} / \mathrm{mm}$.

a. Channel 1 modulated $100 \%$

b. channel 2 modulated $100 \%$

C. channel 3 modulated 100\%

d. channel 4 modulated 100\% 


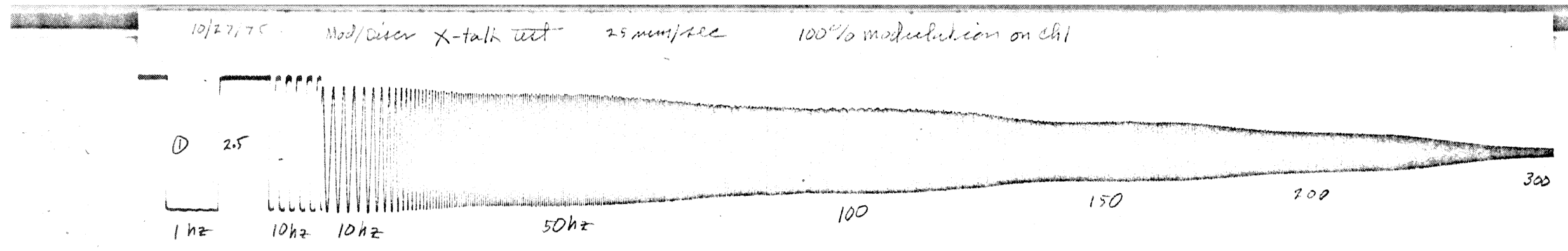

(2)

(3) .1

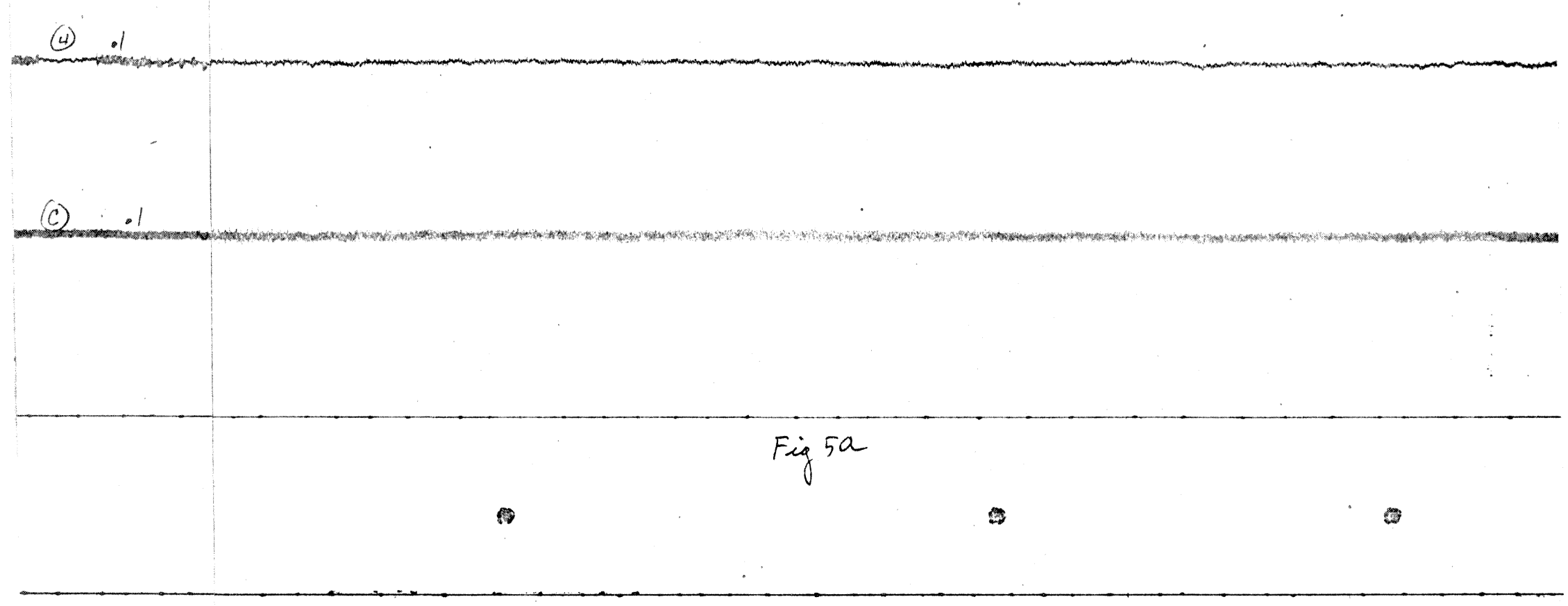




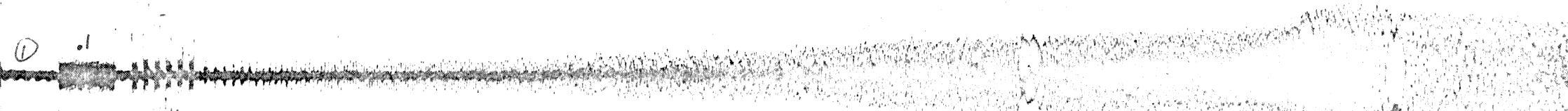

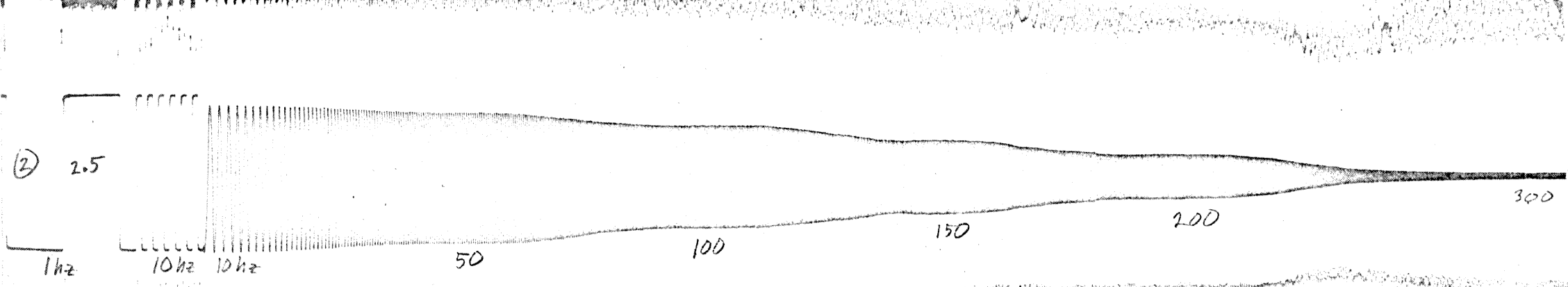
(3) . 1 (n) (4). (c) .1

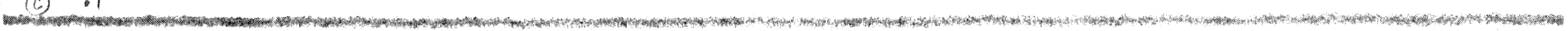

$\$$
6
粉
2 


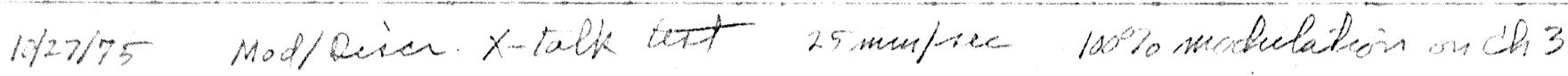

(1).

20. 1

(2).1

lhz $10 \mathrm{hz} 10 \mathrm{hz}$

50

100

150

(3) 2.5

200

300

$\Theta .1$

(c).

Fig $5 C$

*

c) 


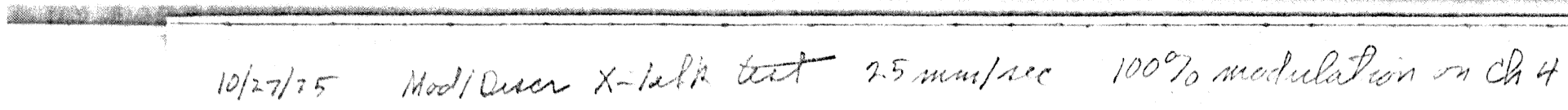

(1).

(2) 1

(3).

$1 h z, 10 h z, 10 h z$

50

100

150

200

(4) 2.5

300

(c) 0.1

Fig $5 d$

to

* 
Figure 6 Noise (and dynamic range) tests of the broad-band multiplex system recorded and played back on the sony cassette recorder with the use of subtractive compensation. A $2 \mathrm{hz}$ square wave at modulation levels of $0 \mathrm{db}(100 \%),-10 \mathrm{db},-20 \mathrm{db}, \cdots,-60 \mathrm{db}(0.1 \%)$ was imposed on the 4 data channel modulators, and the multiplexed subcarriers were recorded on the Sony recorder. The multiplexed subcarriers were then played back on the sony, detected by the broad-band discriminators using subtractive compensation, and recorded on the Oscillomink. The sensitivity settings are indicated on the figure: $2.5 \rightarrow 125 \mathrm{mv} / \mathrm{mm}$, $1.0 \rightarrow 50 \mathrm{mv} / \mathrm{mm}, .25 \quad 12.5 \mathrm{mv} / \mathrm{mm}$, and .10 $\rightarrow 5 \mathrm{mv} / \mathrm{mm}$. Compare these tests with those for the modulator/discriminator combination (omitting tape record and playback, shown in Figure 3.)

a. All for data channels

b. Channels 1 through 3 (4 deleted) 


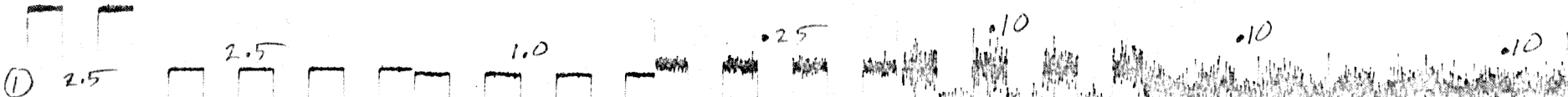

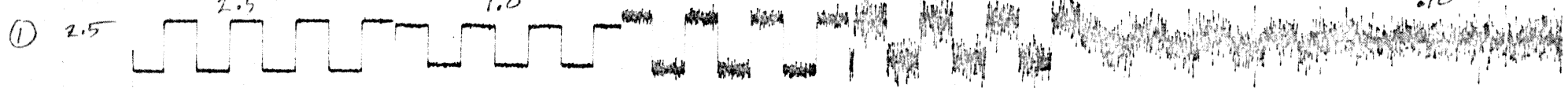

$-L$

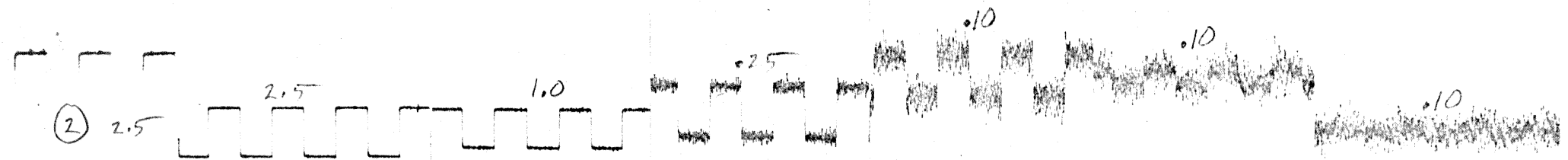

$-L$

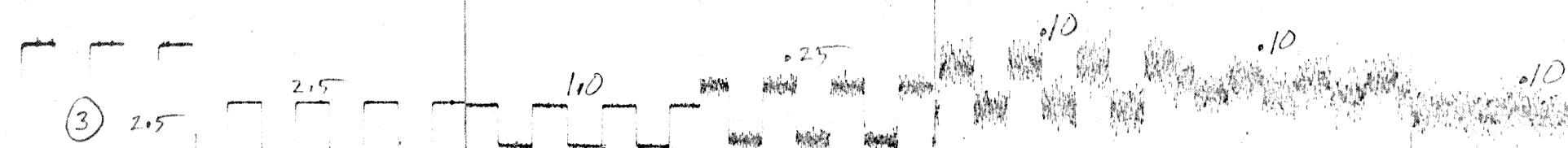

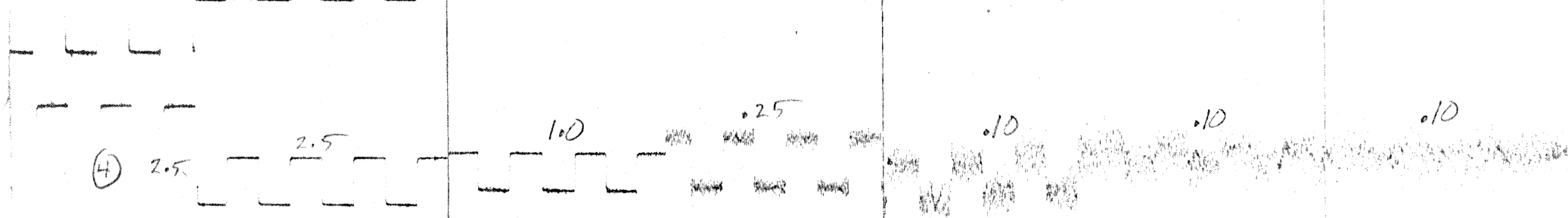

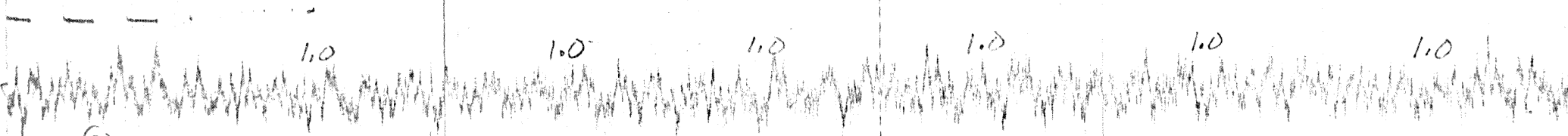

(c) 1.0 


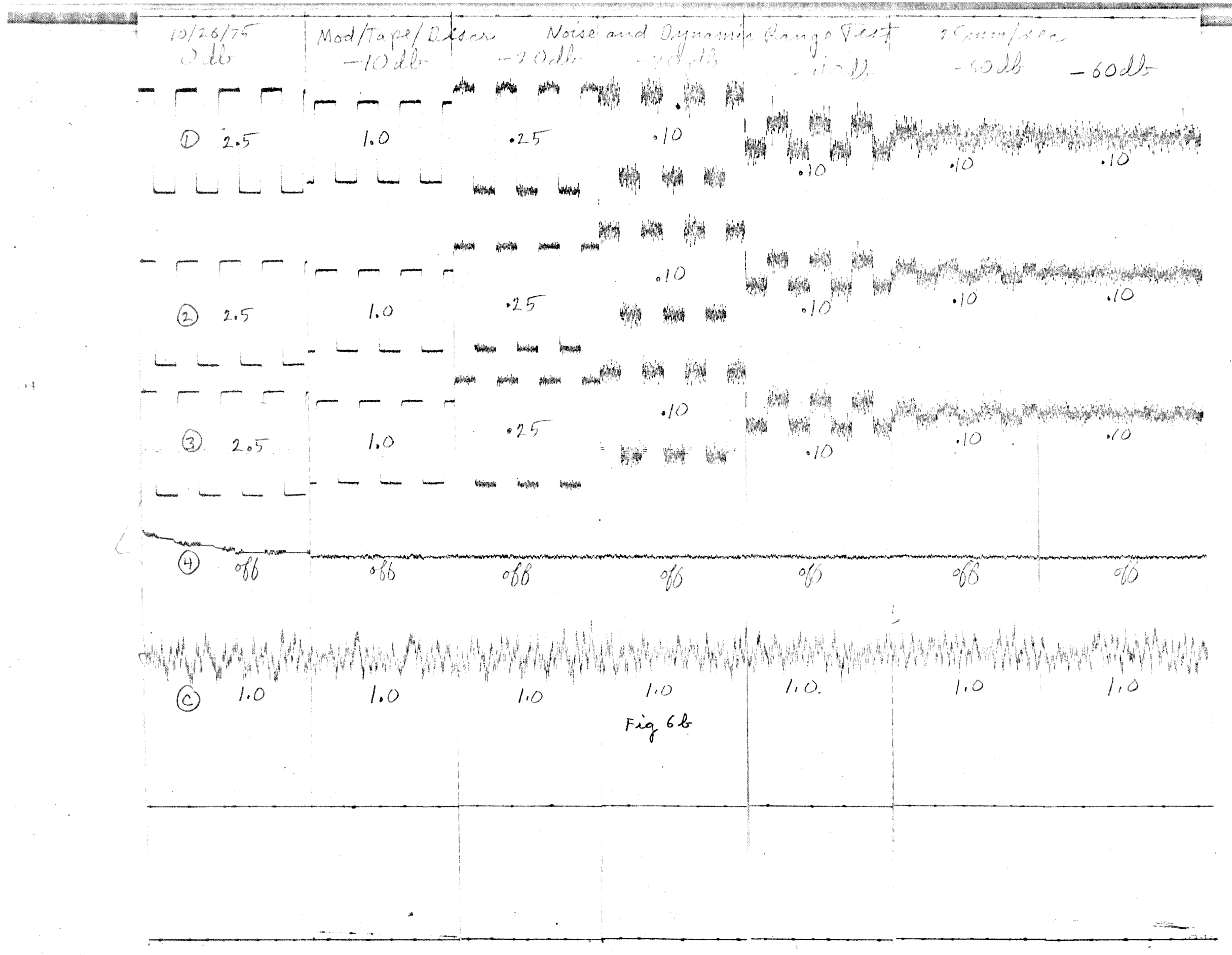


Figure 7 Crosstalk tests of the broad-band multiplex system recorded and played back on the Sony cassette tape recorder. On each test one data channel was modulated at the $0 \mathrm{db}$ (100\%) level by a $10 \mathrm{hz}$ square wave and by a 10 to $300 \mathrm{hz}$ swept frequency sine wave, and the other data channels and compensation channel were unmodulated. The modulated channel was recorded on the Oscillomink at a setting of 2.5 (125 mv/mm); the compensation channel, at a setting of $1.0(50 \mathrm{mv} / \mathrm{mm})$; and the unmodulated data channels, at a setting of 0.10 ( $5 \mathrm{mv} / \mathrm{mm})$. Compare these results with those shown in Figure 5 for the modulator/ discriminator combination without tape recoring and playback.

a. Channel 1 modulated $100 \%$

b. Channel 2 modulated $100 \%$

c. Channel 3 modulated 100\%

d. Channel 4 modulated 100\% 


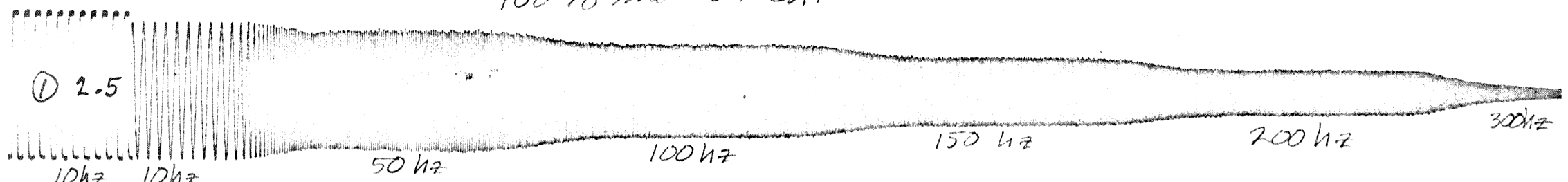

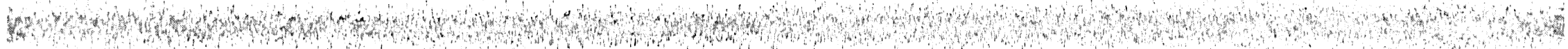
(2) 0.1 .

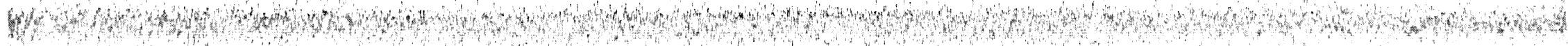
(3) 0.1

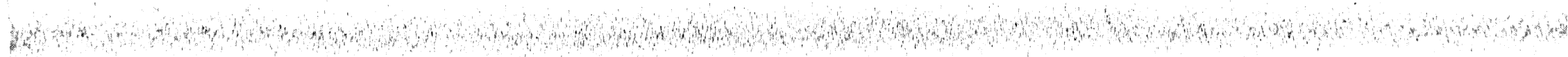
(4) 0.1

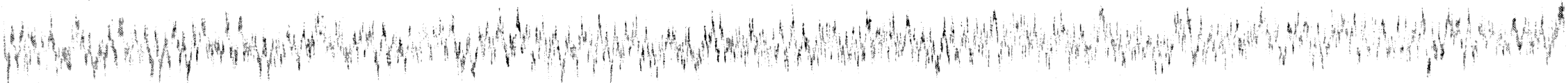
(c) 1.0 


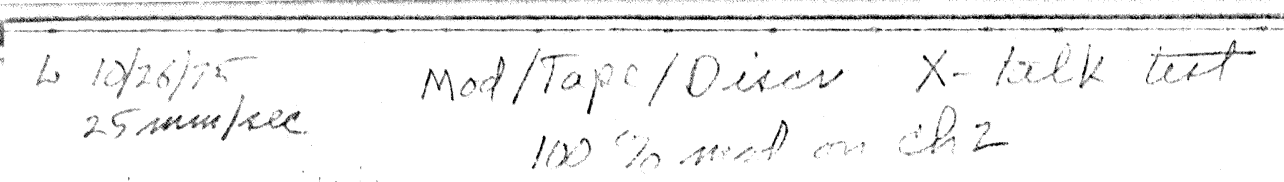

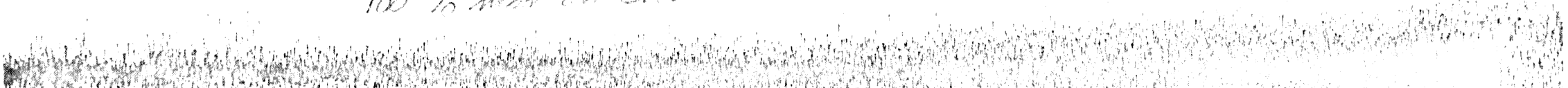

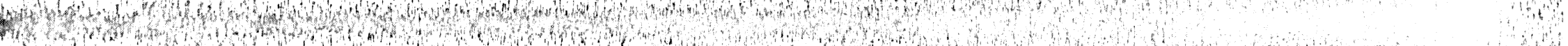

(1) 0.1

$\sim^{1 h z}-10 h z 10 h z \quad 50 h z$

(2) 2.5

100h:

150hz

roohz

-

(3) 0.1 .

(4) 0.1

What

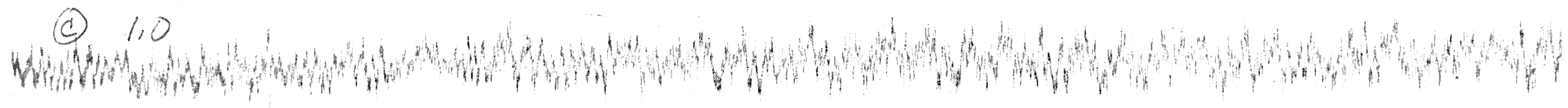

\section{Feg $7 b$}

m

$\$$

3

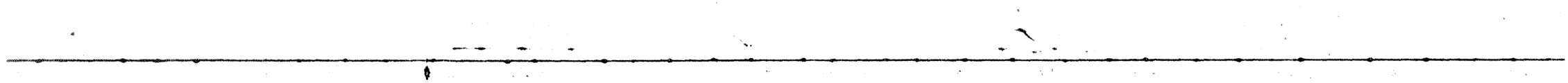




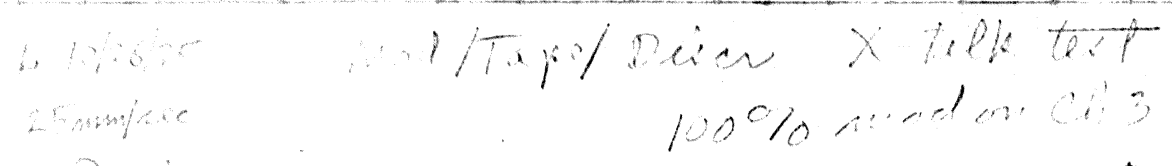

Q $Q$

Q

00.1

(3)

(4)

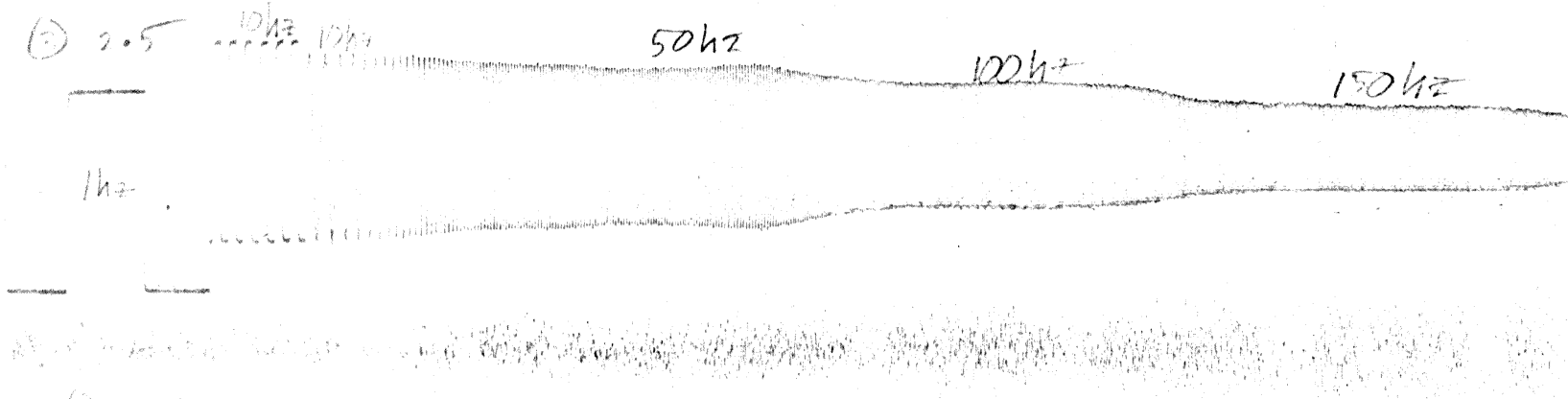

(4) 0.1

Hat

(c) 1.0

\section{Feg $7 C$}




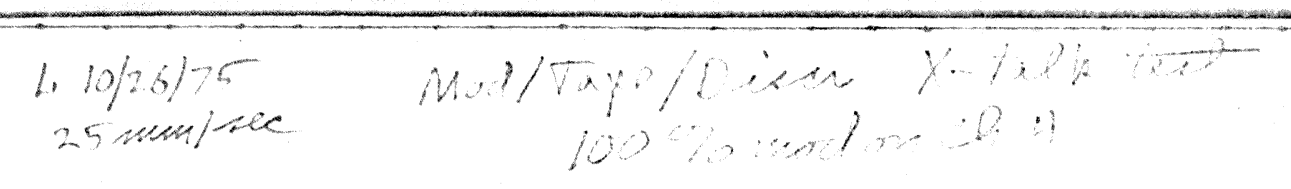

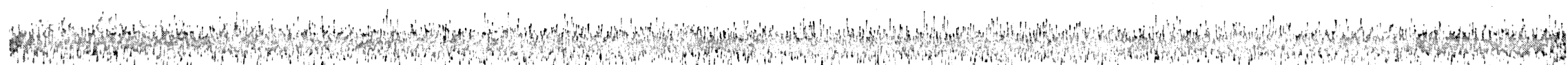
(1) 0.1

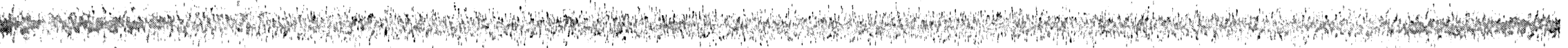
(2) 0.1

(3) 0.1

Whentw wo (3)

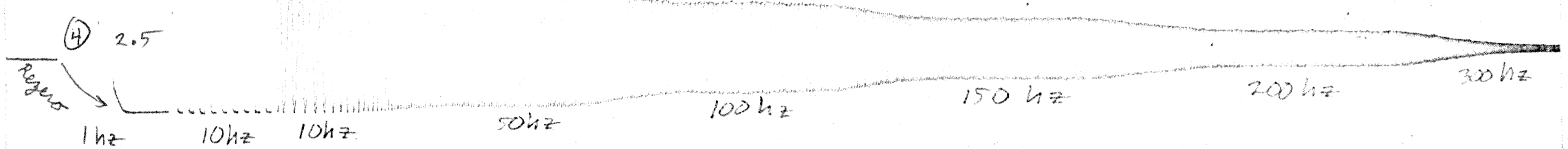

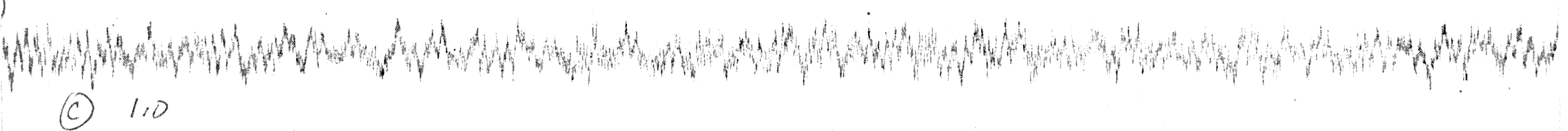

\section{Feg $7 d$}


Figure 8 Compensation effectiveness tests for the broad-band multiplex system recorded and played back on the sony cassette recorder. A 2 hz square wave at modulation levels from $0 \mathrm{db}(100 \%)$ to $-60 \mathrm{db}(0.1 \%)$ was imposed on the modulators, recorded and played back on the tape recorder, detected by the broad-band discriminators, and played out on the Oscillomink. Sensitivities cocorresponding to the various Oscillomink settings are: $2.5 \rightarrow 125 \mathrm{mv} / \mathrm{mm}, 1.0 \rightarrow 50 \mathrm{mv} / \mathrm{mm}, .25 \rightarrow 12.5 \mathrm{mv} / \mathrm{mm}$, and $0.1 \rightarrow 5 \mathrm{mv} / \mathrm{mm}$. At each modulation level the playback was carried out both with and without compensation.

a. All four channels, played out at relatively low Oscillomink sensitivities,

b. all four channels, played out at relatively high Oscillomink sensitivities,

c. channels 1 through 3 (channel 4 deleted) played out at relatively high oscillomink sensitivities. 


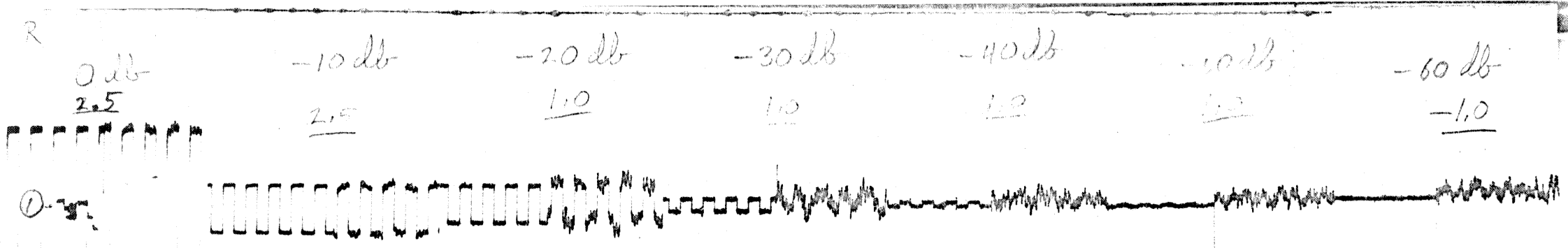

(2)

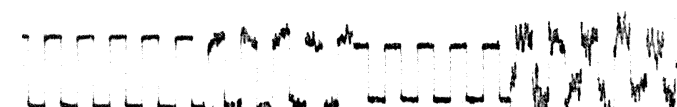
$-\operatorname{coch}$

(3)

$$
\text { (3) }
$$

(4)

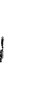

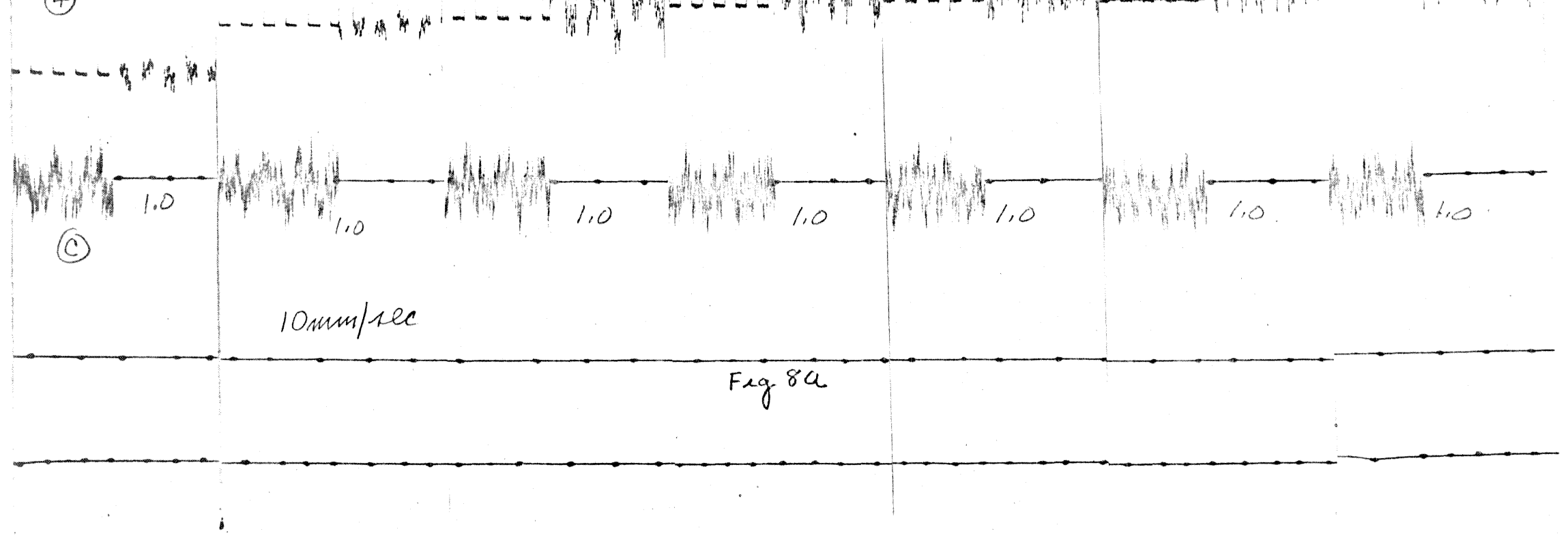



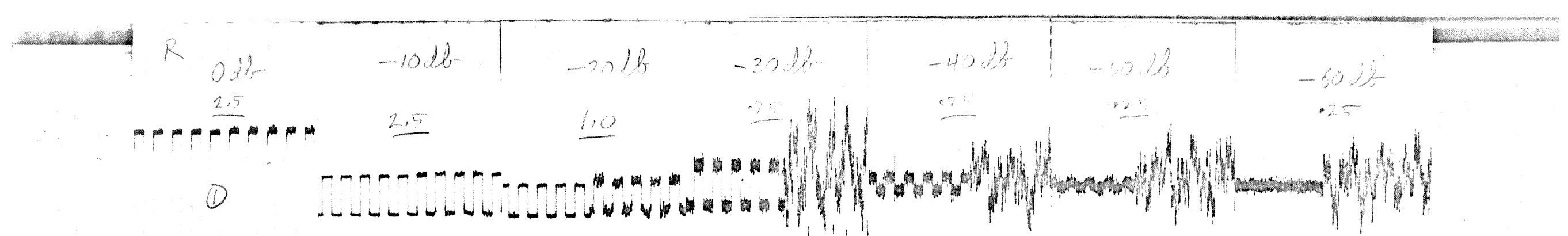

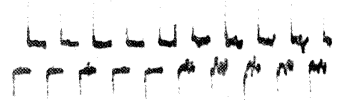

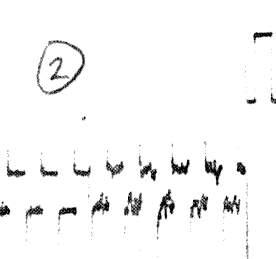

(3) -

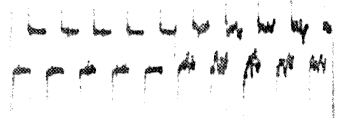

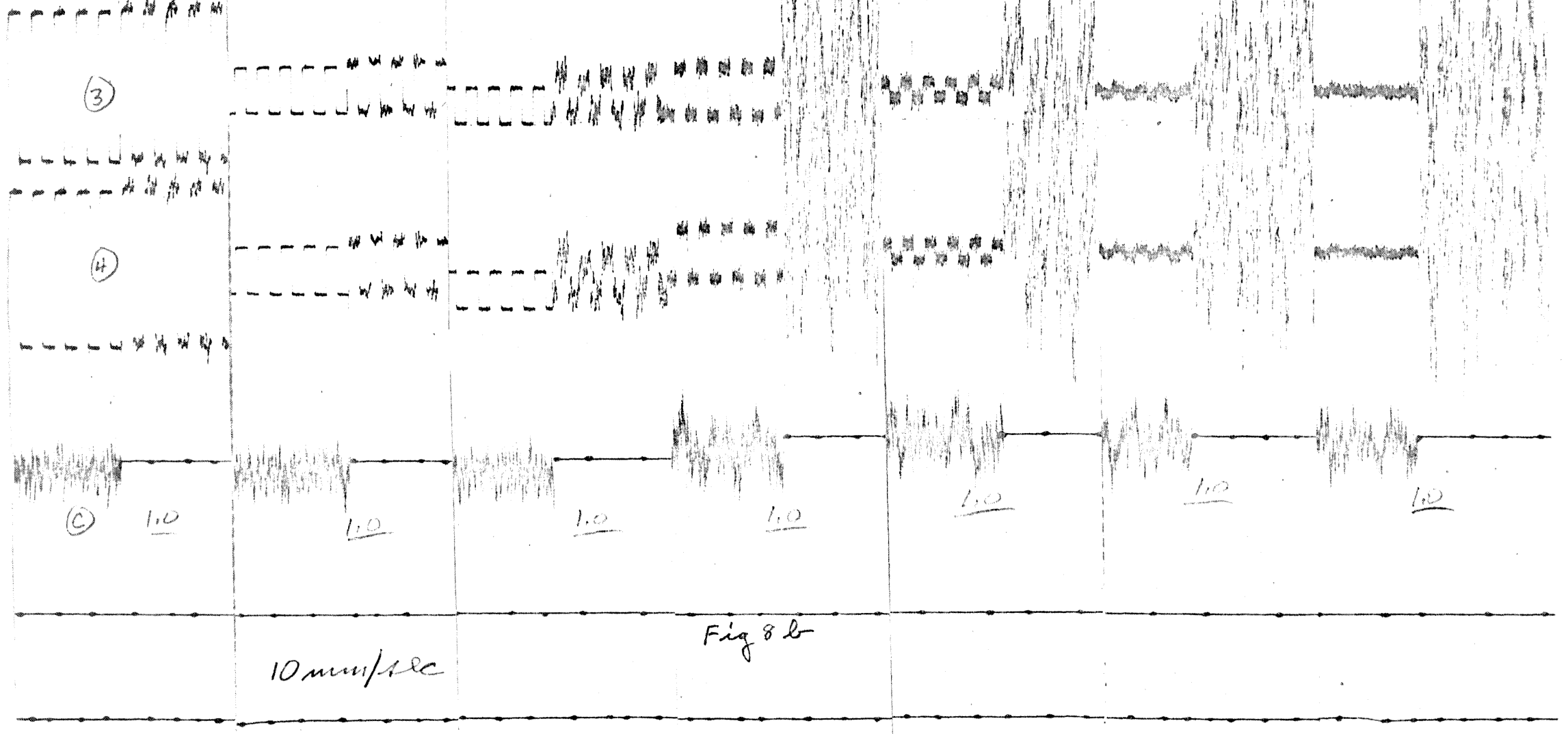


masuoblith

$401 \%$

$-502$

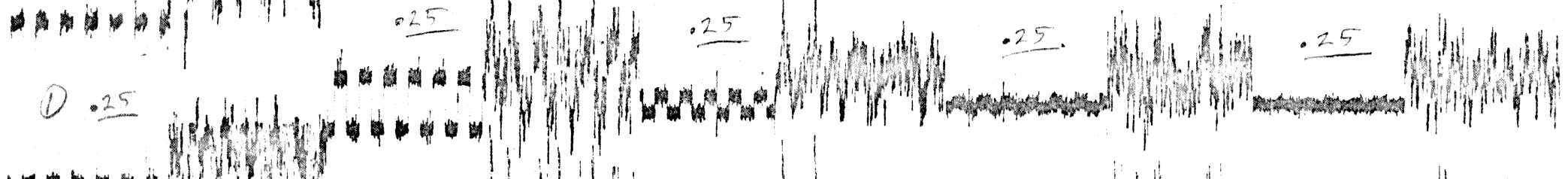
1 w

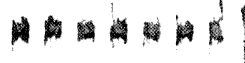

(3).

- in

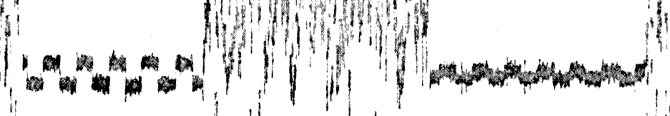

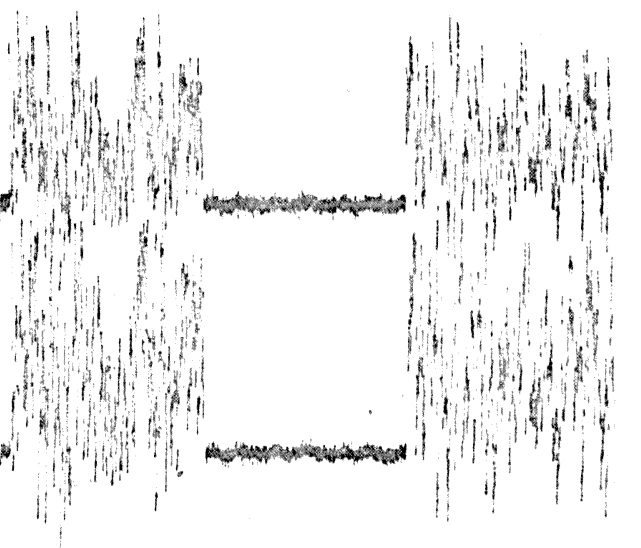

o w o num

(4) of

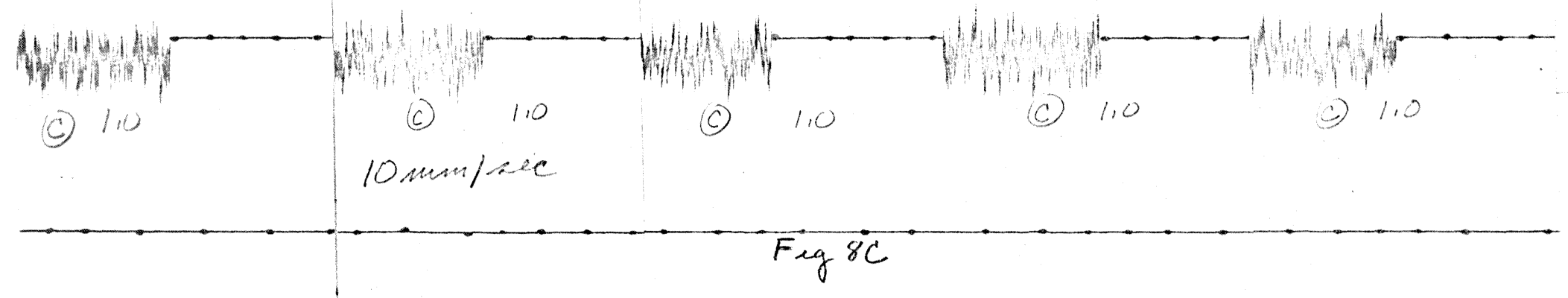


Figure 9 Bias and "modulation" level tests on the 5-day-tape system adaptation of the broad-band multiplex system. The top trace is from a time code generator. Traces 2 through 5 are playouts of data channels 1 through 4 , which were modulated by a $1 / 2 \mathrm{hz}$ square wave at the

- $40 \mathrm{db}$ level. Trace 6 is the output of the compensation discriminator. (Traces 2 through 6 were derived from a multiplexed signal recorded on a single tape track). Trace 7 is the output of an FM data track (center frequency $338 \mathrm{hz}$, maximum deviation \pm 40\%) which was modulated by the same $1 / 2 \mathrm{hz}$ square wave at the - $40 \mathrm{db}$ level and was played out through a $125 \mathrm{hz}$ high-cut Krohn-Hite filter.

a. Multiplex data signal* at a level of $12.5 \mathrm{mv}$ peak to peak and bias signal* at $0.9 \mathrm{~V}, 1.1 \mathrm{~V}, 1.25 \mathrm{~V}, 1.4 \mathrm{~V}$, and $1.6 \mathrm{~V}$ (from left to right).

b. Multiplex data signal* at a level of $15.0 \mathrm{mv}$ peak to peak and bias signal* at a level of $0.9 \mathrm{~V}, 1.1 \mathrm{~V}, 1.25 \mathrm{~V}, 1.4 \mathrm{~V}$, and $1.6 \mathrm{~V}$ (from left to right).

Oscillomink sensitivity settings of 2.5 and 0.25 correspond to sensitivities of $125 \mathrm{mv} / \mathrm{mm}$ and $12.5 \mathrm{mv} / \mathrm{mm}$, respectively.

* Measured at the output of the summing amplifier (in which the bias and modulation signals are combined) which drives the recording head in series with a $10 \mathrm{ohm}$ resistance. 
(2) .25

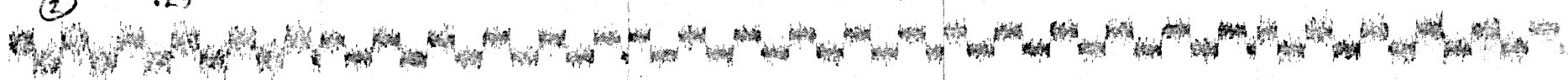

(3) .25

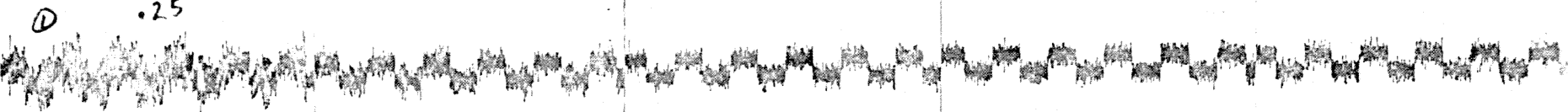

20.

(4) .25

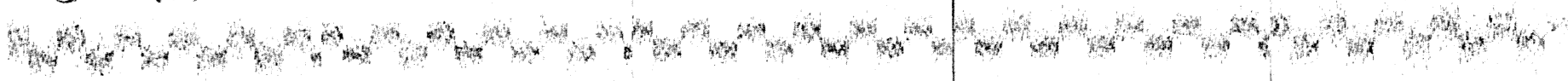

(c) 2.5

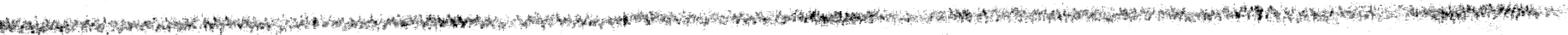

$$
\begin{aligned}
& \text { FM } \quad .25
\end{aligned}
$$

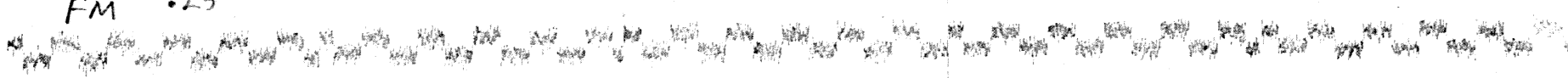

$$
\begin{aligned}
& \text { - Hodb mod Feg } 9 a
\end{aligned}
$$




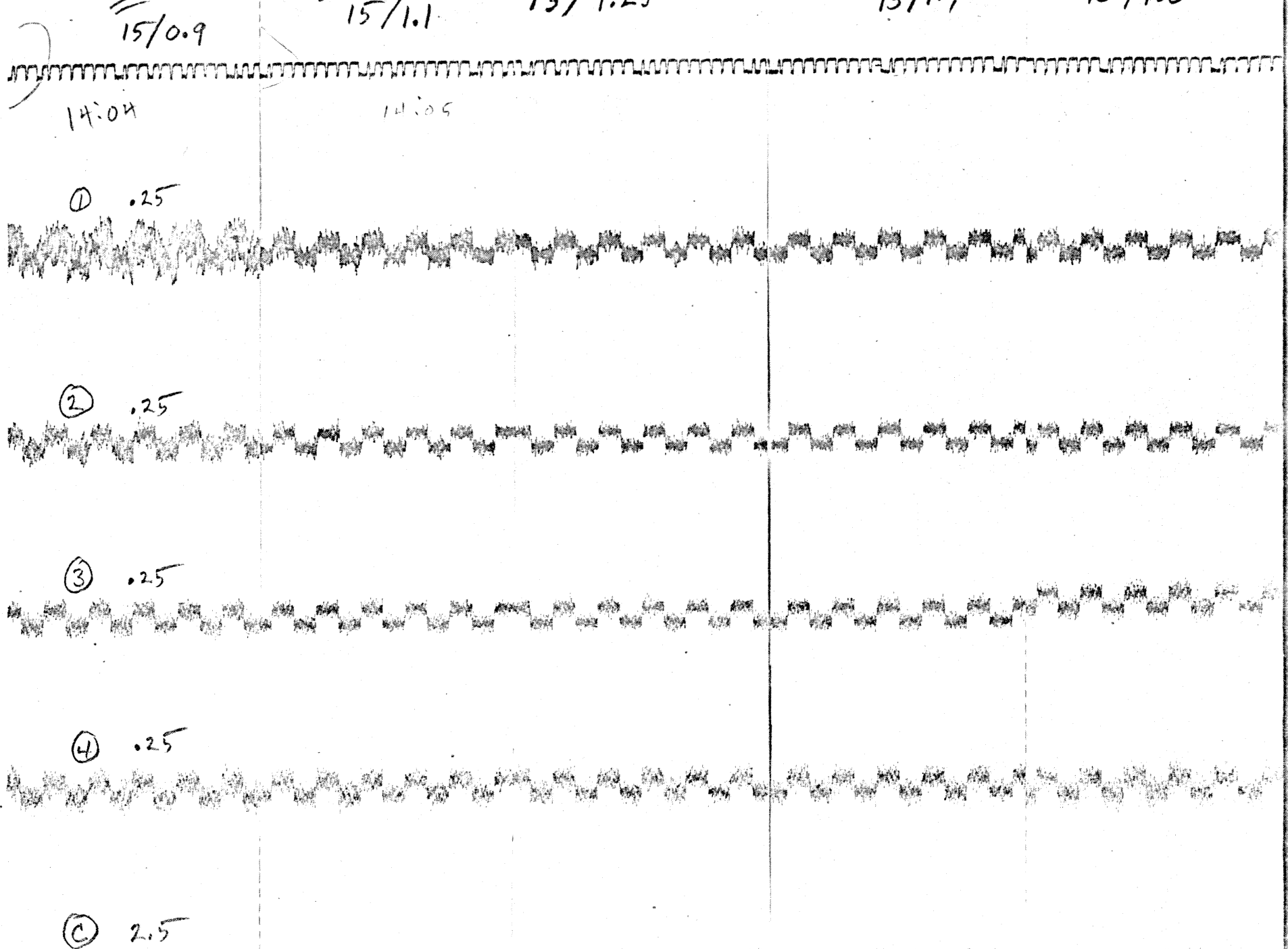

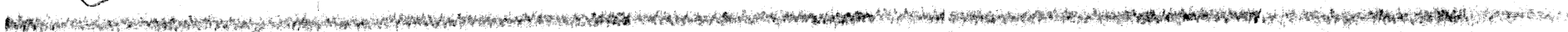

$F M .25$

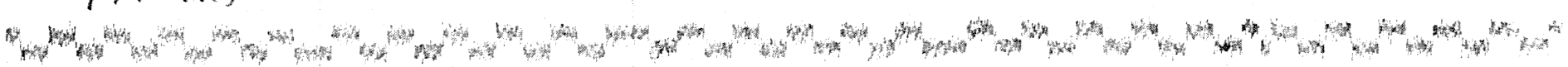

$$
\begin{aligned}
& \text { Fig } 9 b
\end{aligned}
$$


Figure 10 Compensation test on the 5-day-tape system adaptation of the broad-band multiplex system. A $1 \mathrm{hz}$ to $50 \mathrm{hz}$ swept-frequency sine wave at the - $10 \mathrm{db}$ level was applied as a "proportional" modulation to the data channels and the compensation channel. The deviation produced by this arrangement is $\delta \mathrm{F}_{\mathrm{Ci}}+. .316 \times 40 \times \frac{\mathrm{F}_{\mathrm{Ci}}}{625} \mathrm{hz}$, corresponding to a tape speed variation of about $\pm 2 \%$. The frequencies indicated on the FM trace (uncompensated) correspond to recorded data frequencies. Oscillomink settings of 1.0 and 0.25 correspond to sensitivities of $50 \mathrm{mv} / \mathrm{mm}$ and $12.5 \mathrm{mv} / \mathrm{mm}$, respectively. 

Figure 11 Effect of output filter cutoff frequency on the output noise level of the 5-day-tape F.M. record channels, A $1 / 2$ hz square wave at a modulation level of - $30 \mathrm{db}(3.2 \%)$ was recorded on all four multiplex channels and on a separately recorded F.M. channel. On playback (at 5 times recording speed) a Krohn-Hite variable high cut filter was connected between the output of the F.M. channel and the Oscillomink. The F.M. signal was played out at a variety of high cut filter settings (cutoff rate of $42 \mathrm{db} /$ octave, which are indicated above the F.M. channel trace. The corresponding data cutoff frequencies are indicated below the trace. 


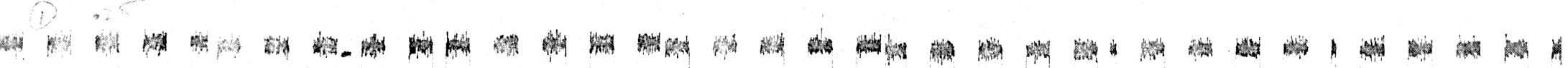

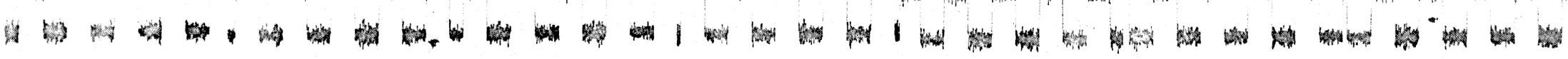

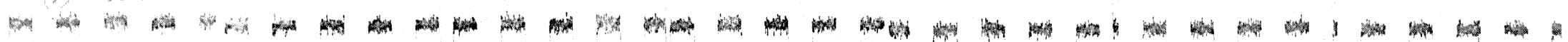

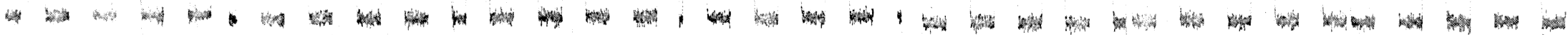

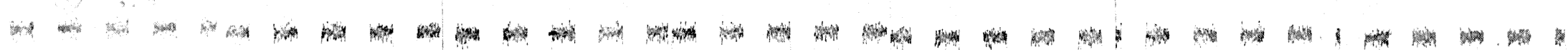

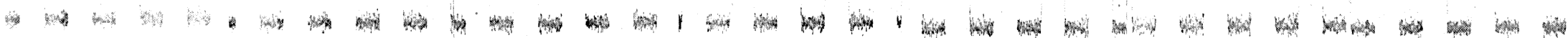

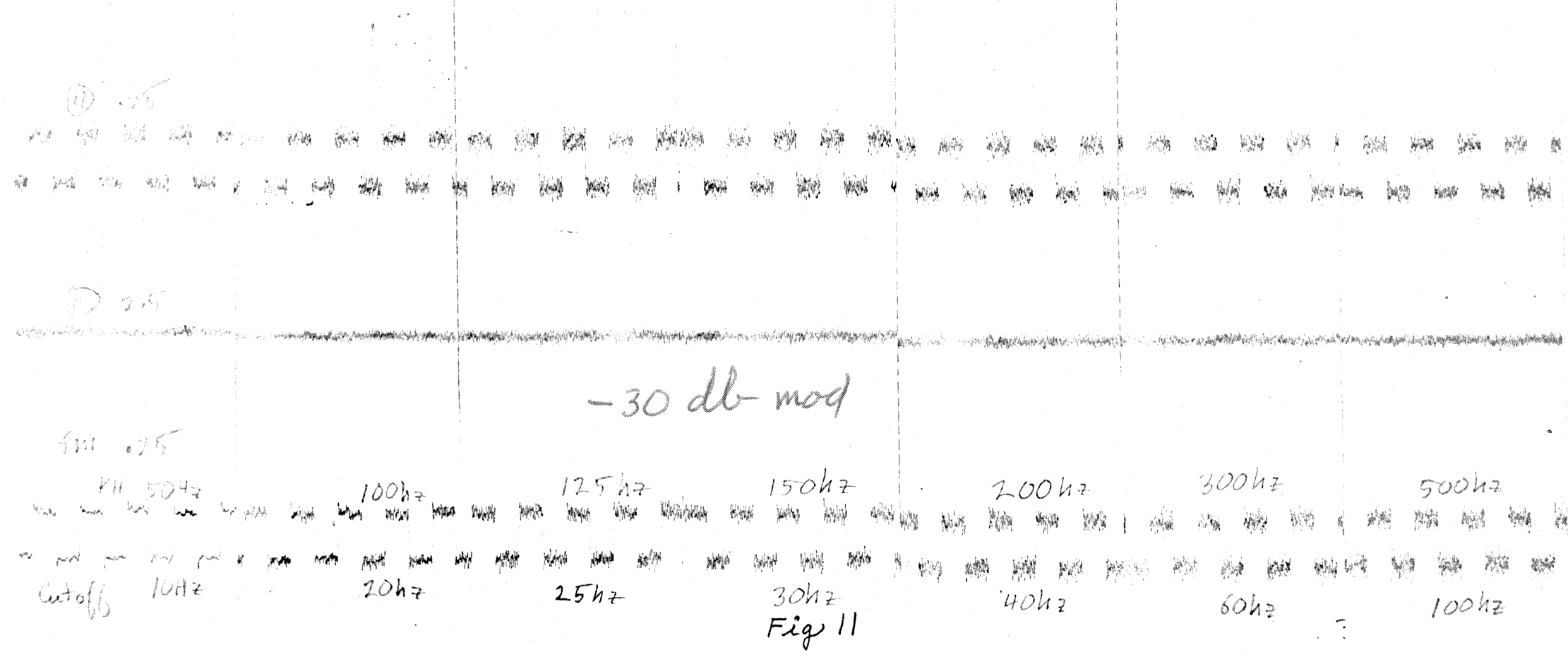


Figure 12 Noise (dynamic range) tests of the 5-day-tape system adaptation of the broad-band multiplex system. A $1 / 2 \mathrm{hz}$ square wave at modulation levels of - $20 \mathrm{db}(10 \%),-30 \mathrm{db},-40 \mathrm{db}$, and - $50 \mathrm{db}(0.32 \%)$ was imposed on the data channel modulators and recorded at a speed of 15/80 ips on the P.I. 5100 tape recorders. The tape was played back at 15/16 ips on the B \& H 3700B reproduce machine and detected by the broad-band discriminators, with compensation. Oscillomink settings of 2.5 and 0.25 correspond to sensitivities of $125 \mathrm{mv} / \mathrm{mm}$ and $12.5 \mathrm{mv} / \mathrm{mm}$, respectively.

a. All four data channels

b. Channels 1 through 3 (4 deleted on recording) 


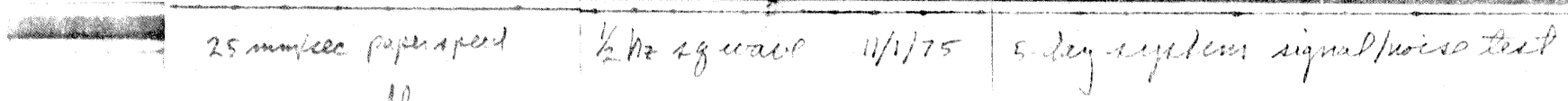

$-20 \mathrm{db}$

* - 30 d 2

$-1, i b$

$-50 d b^{-}$

(1)

-

2) $\quad .25$

$$
\text { 1. }
$$

-

1)

(3) .25

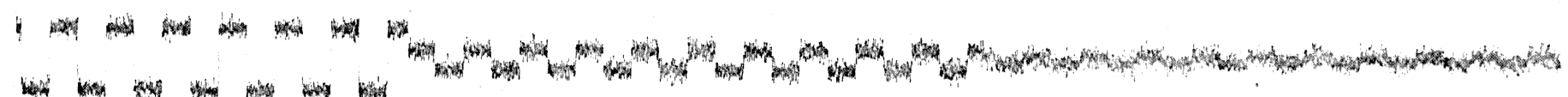

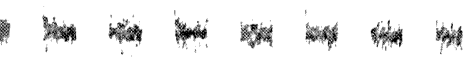

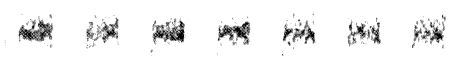

(4) .25

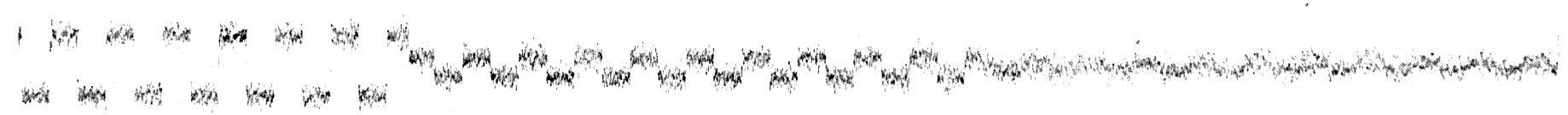

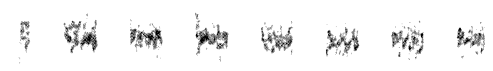

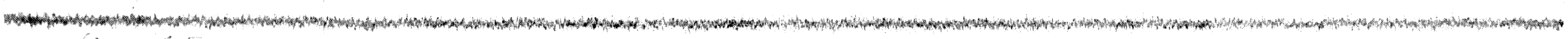

(c) 2.5

$$
1 \text { mons }=12.5 \text { wer }
$$

Fig $12 a$ 
$200-200$

2

matree pire
$-20 d b$

W w

$-302 b$

boley as

(1)

(1)

$-40 \&$

equallewestat

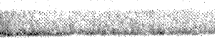

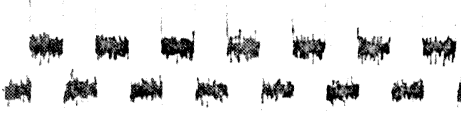

(2) .25

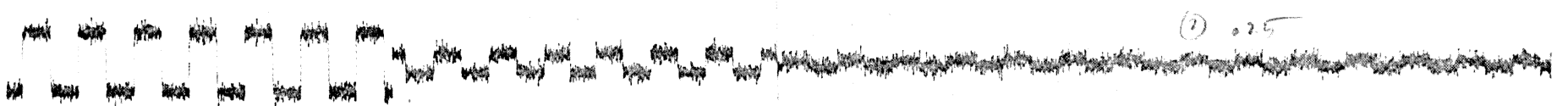

(2)

(3)

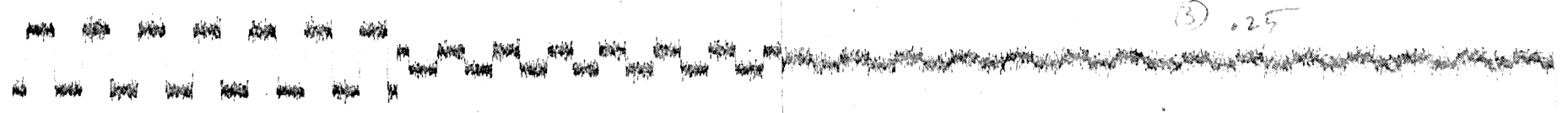

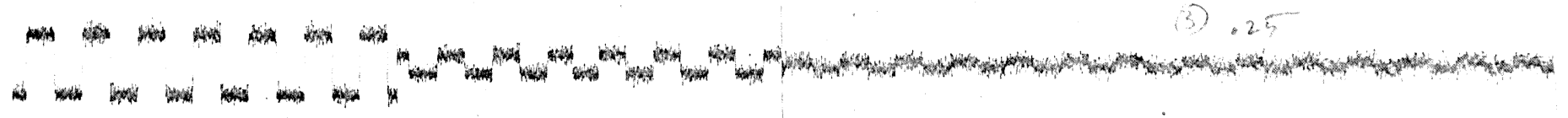

$-50 \mathrm{db}$

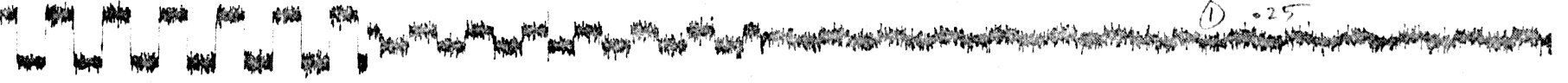

(4) off

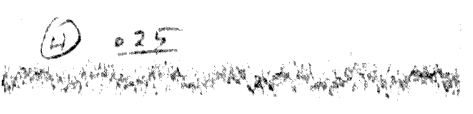

(C) 2.5

() 2.5

Feg $12 b$ 
Figure 13 Frequency response tests of the 5-day-tape system adaptation of the broad-band multiplex system. A $1 \mathrm{hz}$ to $100 \mathrm{hz}$ swept-frequency sine wave at modulation levels of $0 \mathrm{db}(100 \%),-10 \mathrm{db}$, and $-30 \mathrm{db}(3.2 \%)$ was applied to the modulators of the multiplex system on all three tests and to the modulator of the straight F.M. system recorded on a separate tape track on the last two tests. The frequencies indicated on the playback refer to data frequencies at record time. Because the playback was carried out at 5 times recording speed, the discriminators saw frequencies at 5 times their "record time" values.

\begin{tabular}{|c|}
\hline a. $0 \mathrm{db}$ modulation (100\%) \\
\hline \hline b. $\quad-10 \mathrm{db}$ modulation $(32 \%)$ \\
\hline \hline c. $\quad-30 \mathrm{db}$ modulation (3.2\%) \\
\hline
\end{tabular}

As on earlier figures, Oscillomink sensitivities were: $2.5 \rightarrow 125 \mathrm{mv} / \mathrm{mm}$. $1.0 \rightarrow 50 \mathrm{mv} / \mathrm{mm}, .25 \rightarrow 12.5 \mathrm{mv} / \mathrm{mm}$. For the F.M. traces on $\mathrm{b}$ and $\mathrm{c}, \mathrm{a}$ high-cut filter of $125 \mathrm{hz}$ ( $25 \mathrm{hz}$ data frequency) was used to permit more accurate comparison with the multiplexed traces. 

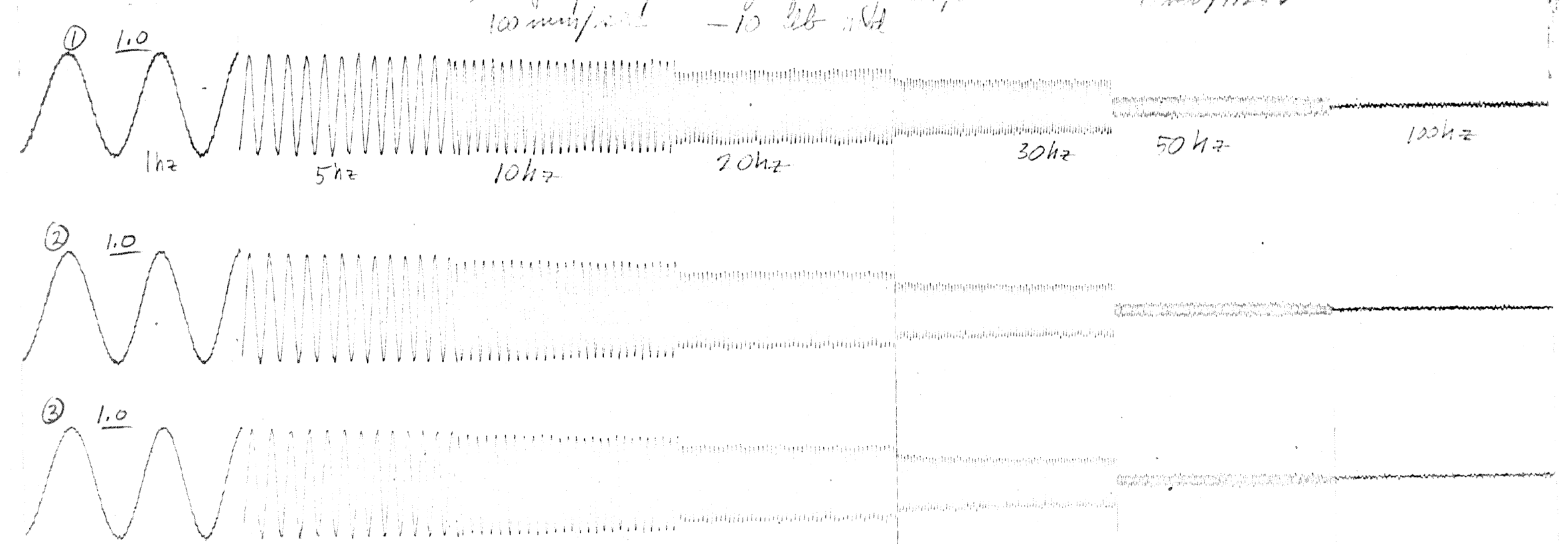

(4) 1.0

(c) 1.0

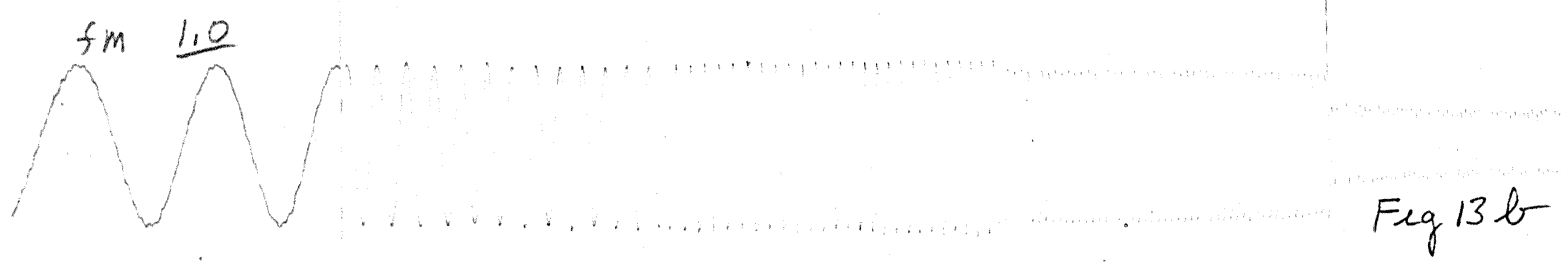




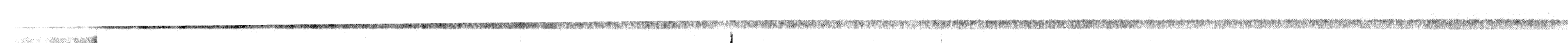


Figure 14 Crosstalk tests on the 5-day-tape system adaptation of the broad-band multiplex system. Compare with Figure 5 (modulator/discriminator combination) and Figure 7 (Sony cassette recorder). On each test one data channel was modulated at the $0 \mathrm{db}$ level (100\%) by 0.5 and $5 \mathrm{hz}$ square waves and by a 5 to $100 \mathrm{hz}$ swept frequency sine wave while the other data channels and the compensation channel were left unmodulated. Oscillomink settings of 2.5 and .25 correspond to sensitivities of $125 \mathrm{mv} / \mathrm{mm}$ and $12.5 \mathrm{mv} / \mathrm{mm}$, respectively.

a. Channel 1 modulated at $100 \%$ level.

b. Channel 2 modulated at 100\% level. c. Channel 3 modulated at 100\% level.

d. Channel 4 modulated at $100 \%$ level. 
$1111 / 75$

25 menoficeter

paine

c..

tesp xtatk

$.54 z$

$54+$

i hz

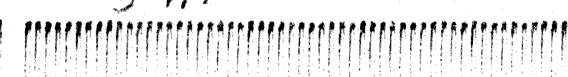

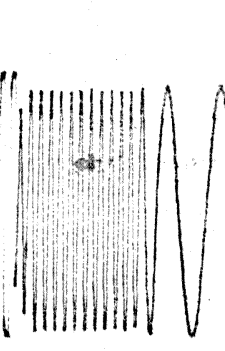

- (1) 2.5

$L L L L L$

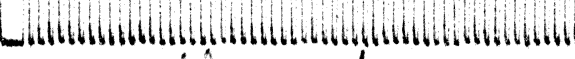

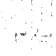

odb $\mathrm{mod}$

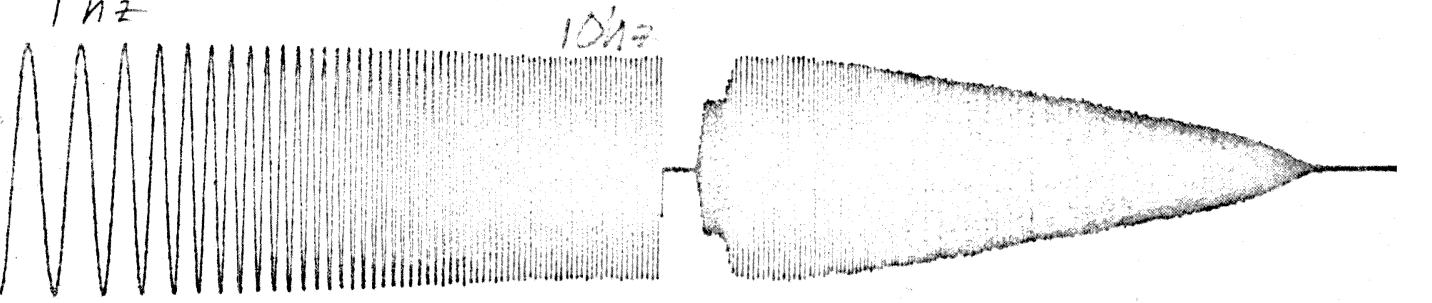

(2) .25

27th

(3) .25

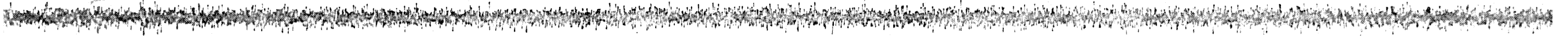

(4) .25

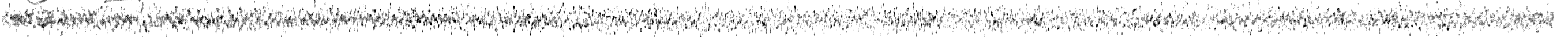

(c) .25

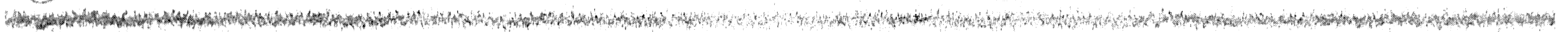
Feg Ha 


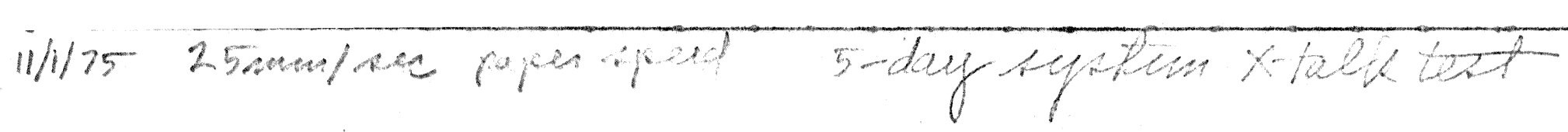

7 (1) .025

(2) 2.5 odbmod

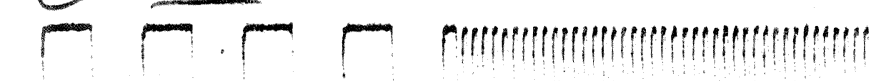

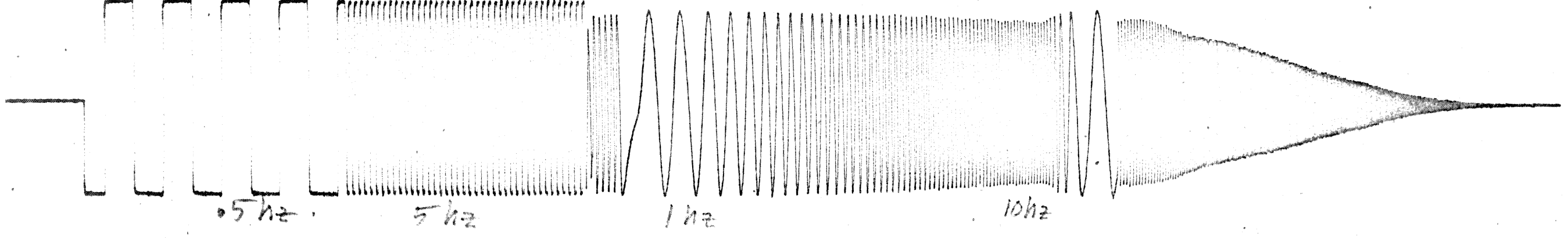

(3) .25

(4) 25

How

(c) 2.5

How Fig $14 b-$ 


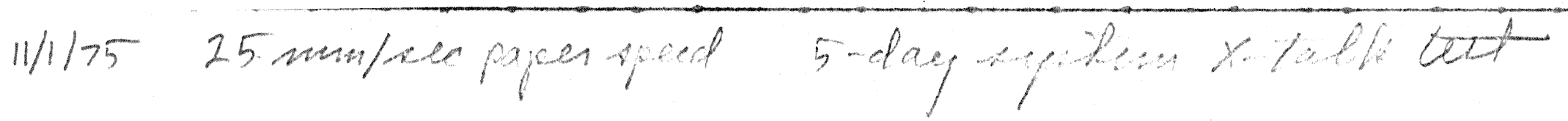

(1) .25

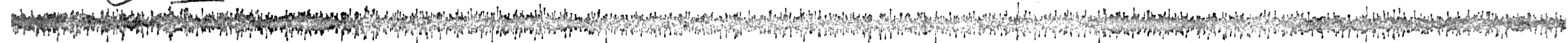

(2). .25 (2) $\frac{25}{25}$,

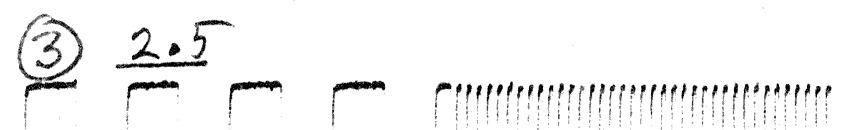

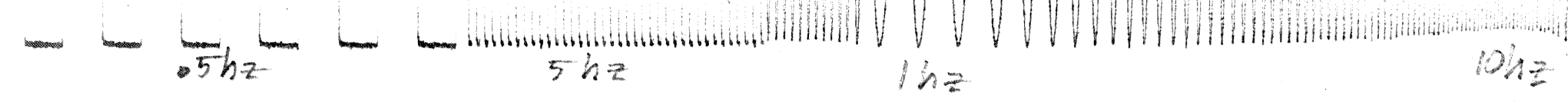

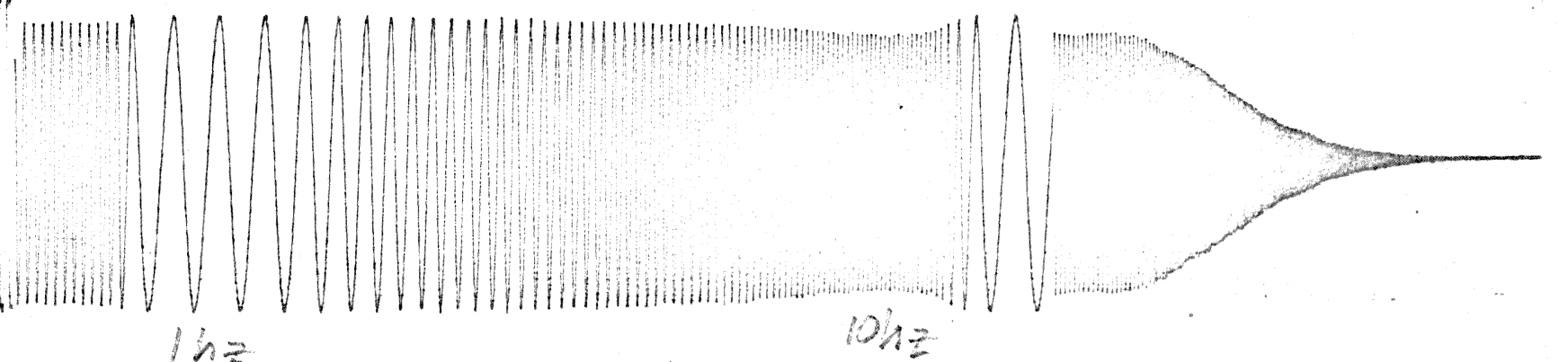

(4) .25

Whow

(C) 2.5

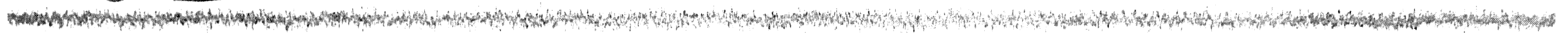

$$
\text { Fey } 14 C
$$


Figure 15 Test of the effectiveness of subtractive compensation with the 5-day-tape system adaptation of the broad-band multiplex system. $1 / 2 \mathrm{hz}$ square waves recorded on all 4 multiplex data channels and on the separate F.M. channel were played back with and without compensation at oscillomink paper speeds of $25 \mathrm{~mm} / \mathrm{sec}$ and $100 \mathrm{~mm} / \mathrm{sec}$. Oscillomink settings of 2.5 and 0.25 correspond to sensitivities of $125 \mathrm{mv} / \mathrm{mm}$ and $12.5 \mathrm{mv} / \mathrm{mm}$, respectively.

a. - $40 \mathrm{db}$ (1\%) modulation level.

b. $\quad-50 \mathrm{db}(0.32 \%)$ modulation level. 
(2).

$10 / 30 / 7$

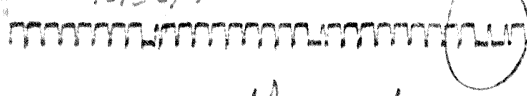

$-40 d b$ wed

H.in

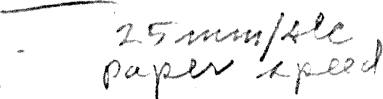

$-40 \mathrm{db}$ wad

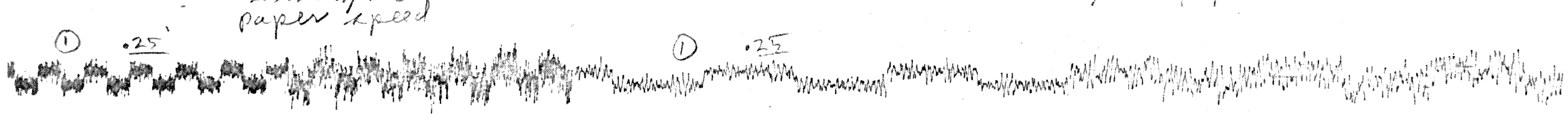

100 mustres poperatped

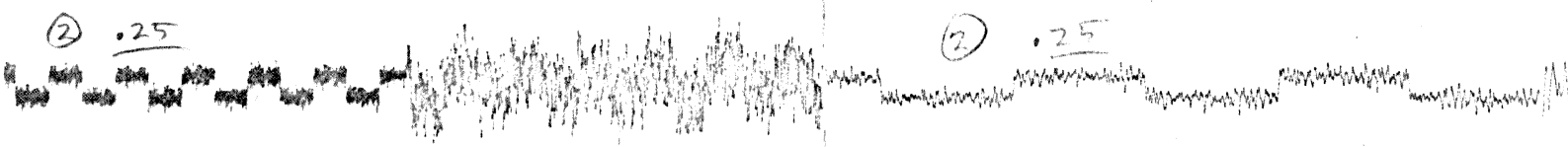

(3) .25

(4) $\frac{.25}{25}+4 \times+4$

(c) 2.5 comp diser. removed

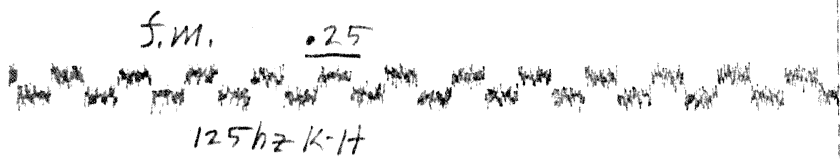

(3) $\cdot 25$

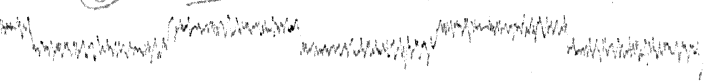

(4) 025

(c) 25

Comp diser removed

Feg $15 a$ 


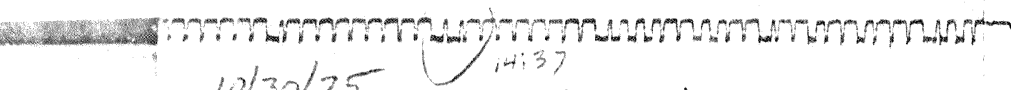

$10 / 30 / 75$

- $50 \mathrm{db}$ ind

$-50 \mathrm{db}$ wed

25 molnee papientped

loo sum/ren papun tiped

(1) .25

(1) 0.25

(2) .25

(2) .25

(3) .25

(4) .25

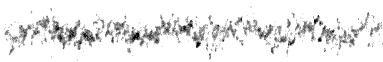

(C) 2.5

Comp deser rimoved

(N)

is.

(3) .25

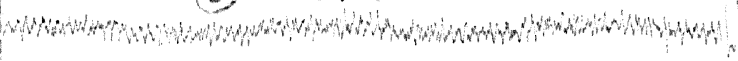

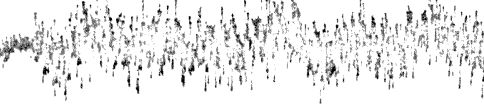

Hownthom

wo

(

(4) .25

(c) 2,5

54.25

Fig $15 \mathrm{~b}$
Comp disen removed fm .25 $125 h_{z} k-H$ 